DOE/PC/9505/--T5

DE-FC22-95PC95051--12

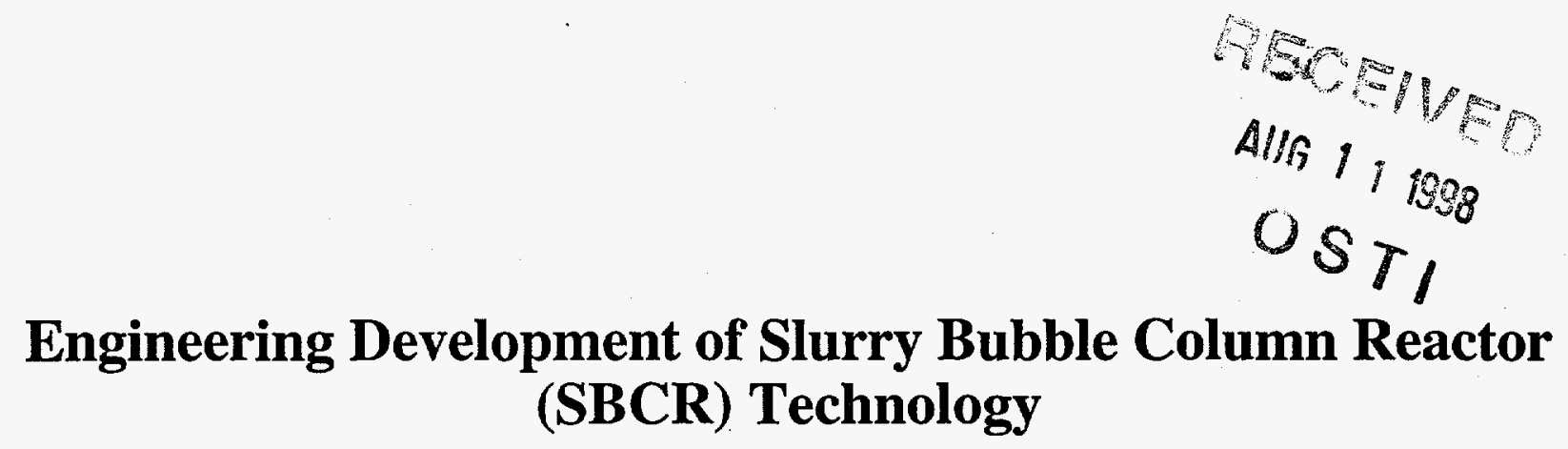

Quarterly Report

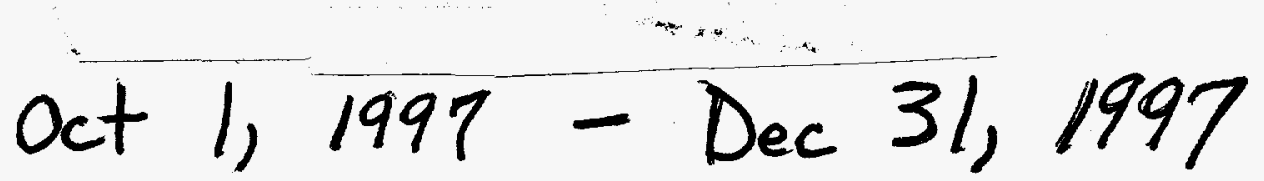

Work Performed Under Contract No.: DE-FC22-95PC95051

For

U.S. Department of Energy

Office of Fossil Energy

Federal Energy Technology Center

P.O. Box 880

Morgantown, West Virginia 26507-0880

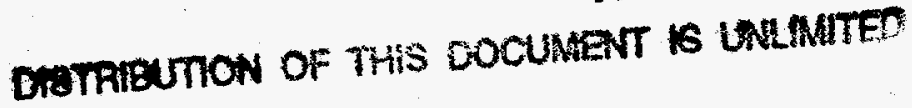

By

Air Products and Chemicals, Inc.

7201 Hamilton Blvd.

Allentown, Pennsylvania 18195-1501 


\section{Disclaimer}

This report was prepared as an account of work sponsored by an agency of the United States Government. Neither the United State Government nor any agency thereof, nor any of their employees, makes any warranty, express or implied, or assumes any legal liabilit or responsibility for the accuracy, completeness, or usefulness of an information, apparatus, product, or process disclosed, or represents that its use would not infringe privately owned rights. Reference herein to any specific commercial product, process, or service by trade name, trademark, manufacturer, or otherwise does not necessarily constitute or imply its endorsement, recommendation, or favoring by the United States Government or any agency thereof. The views and opinions of authors expressed herein do not necessarily state or reflec those of the United States Government or any agency thereof. 


\section{DISCLAIMER}

Portions of this document may be illegible electronic image products. Images are produced from the best available original document. 


\title{
ENGINEERING DEVELOPMENT OF SLURRY BUBBLE COLUMN REACTOR (SBCR) TECHOLOGY
}

\author{
Quarterly Technical Progress Report No. 11 \\ for the Period 1 October - 31 December 1997
}

\section{Contract Objectives}

The major technical objectives of this program are threefold: 1) to develop the design tools and a fundamental understanding of the fluid dynamics of a slurry bubble column Oreactor to maximize reactor productivity, 2) to develop the mathematical reactor design models and gain an understanding of the hydrodynamic fundamentals under industrially relevant process conditions, and 3) to develop an understanding of the hydrodynamics and their interaction with the chemistries occurring in the bubble column reactor. Successful completion of these objectives will permit more efficient usage of the reactor column and tighter design criteria, increase overall reactor efficiency, and ensure a design that leads to stable reactor behavior when scaling up to large diameter reactors.

\section{Summary of Progress}

\section{Task 2: Component Diagnostics Development}

\section{Bubble Size Measurement}

A probe system consisting of a dual-tip probe and the computer code was developed to measure the bubble size distribution in a slurry bubble column under high-pressure, high-temperature, and high-gas-velocity conditions. The dual-tip probe was developed and discussed last quarter. A computer code was developed to process the light intensity signals from a fiber optic probe. This computer code can calculate both the bubble rise velocity and the bubble chord length distribution from the signals.

A single example which shows the bubble column is in the slugging regime at a gas velocity of $34.6 \mathrm{~cm} / \mathrm{s}$ and at $0.1 \mathrm{MPa}$ pressure is provided in this report. The computer code will be used to analyze the bubble size distribution and operating regime in slurry bubble columns under highpressure and high-gas-velocity conditions.

\section{Holdup Measurement with Solids}

A new technique for measuring gas holdup in slurry bubble columns has been developed. The technique has two major advantages: the elimination of uncertain particle density from the measurement and the capability to determine if the particles are completely suspended.

One exciting aspect of both these techniques is that they could be used to make measurements at LaPorte during runs as well as in the laboratory. 


\section{Task 3: Model Selection and Development}

\section{Progress in Evaluation of the Momentum Balance Equation for Bubble Columns Using CARPT and CT Measurements}

Rational model development involves selection of the forces that must be modeled. One way of determining the importance of these forces is to understand the effect of terms in the momentum balance equation. Last quarter we found that the addition of the turbulent drag force to the radial momentum balance improves the agreement for the case of high superficial gas velocity $(12 \mathrm{~cm} / \mathrm{s}$ in a 14-cm-diameter column). However, for the cases of low superficial gas velocity $(4.8 \mathrm{~cm} / \mathrm{s})$, the agreement between the right-hand side (R.H.S.) and the left-hand side (L.H.S.) of the radial momentum balance deteriorated with addition of the turbulent drag force.

Possible sources of the observed discrepancies are evaluated and discussed. The holdup profile was found to have an important effect. The uncertainty of measuring the gas-liquid velocity correlations makes it difficult to determine the importance of these terms. Finally more velocity data are needed near the walls of the bubble column, since gradients are high in this region. This analysis continues.

(Washington University in St. Louis)

\section{Task 4: SBCR Experimental Program}

\section{Effect of Pressure on Gas Holdup at Relatively High Pressures and with Solids}

Gas holdup was measured in a slurry bubble column with a solids concentration of $20 \mathrm{wt} \%$ at $28^{\circ} \mathrm{C}$ and at various pressures using the new holdup measurement technique. The gas holdup increases with an increase in pressure. These measurements will be combined with bubble size measurements to obtain a good picture of flow in high-temperature, high-pressure bubble columns.

(The Ohio State University)

\section{Turbulence Parameters in 18-in. Diameter Columns with and without Internals}

The turbulence parameters (normal and shear stresses and kinetic energy) were evaluated from Computer Automated Radioactive Particle Tracking (CARPT) experiments performed at 2, 5 and $10 \mathrm{~cm} / \mathrm{s}$ superficial gas velocities. These experiments were conducted with the air-drakeoil system in a 44.0-cm (18-in.) diameter column with and without internals. The internals consisted of 16 tubes of 1-inch diameter, which simulate the heat exchanger in the 18-in.-diameter column used in the Alternative Fuels Development Unit (AFDU) in LaPorte, Texas. A perforated plate distributor with hole diameter equal to $0.77 \mathrm{~mm}$ and open area equal to $0.076 \%$ was used. These data will allow us to begin to understand the effect of internals on flow patterns in reactors.

(Washington University in St. Louis) 


\section{Task 6 : Data Processing}

Establishment of the Relationship between the Axial Dispersion Coefficient and Parameters of the Phenomenological Recycle with Cross Flow and Eddy Diffusion Model

The axial dispersion model is simple and relatively easy to use. However, a vital parameter, the dispersion coefficient, is difficult to obtain for scaleup. Our new model should give better scaleup information, but is relatively difficult to use. This new analysis allows the estimation of the dispersion parameter from an equation that is more amenable to the estimation of scaleup performance.

A Taylor-type analysis of the two-dimensional convection-diffusion model for liquid mixing in a bubble column (which was developed and reported in the seventh and eighth quarterly reports) was performed to establish a relationship between the axial dispersion coefficient and the parameters of this new phenomenologically based model. While the recycle with cross flow model describes the phenomena that contribute to liquid mixing in a bubble column more reasonably than the axial dispersion model (ADM), the existence of only one parameter (the axial dispersion coefficient) makes the ADM still attractive to many. Therefore, we have developed a procedure to estimate the axial dispersion coefficient from the parameters of the phenomenologically more correct model. 


\section{The Ohio State University Research}

The following report from Ohio State University for the period contains these brief chapters:

\section{Highlights}

Work Performed

1. Development of Fiber Optic Probe System

2. Effect of Pressure on the Gas Holdup of Slurry Bubble Column 


\section{INTRINSIC FLOW BEHAVIOR IN A SLURRY BUBBLE COLUMN UNDER HIGH PRESSURE AND HIGH TEMPERATURE CONDITIONS}

(Reporting Period: October 1 to December 31, 1997)

\section{Highlights}

1. A computer code was developed to process the light intensity signals from a fiber optic probe. The computer code can calculate the bubble rise velocity and bubble chord length distribution from the signals.

2. It was proven in experiments that the probe system and the computer code can be used to measure the bubble size distribution in a slurry bubble column under high-pressure, hightemperature, and high-gas velocity conditions.

3. A new technique was established to measure gas holdup in slurry bubble columns. The new technique has two major advantages over other techniques: elimination of uncertain particle density from the measurement and the capability to determine if the particles are completely suspended.

\section{Work Performed}

\section{Development of Fiber Optic Probe System}

In the last quarter, a dual-tip optical fiber probe was developed to measure bubble size distribution in high-pressure slurry bubble columns. Calibration of the probe proved that the probe system can satisfactorily measure the bubble rise velocity and bubble chord length, provided that the signal from the probe is processed appropriately.

A computer code was developed during this quarter to analyze light intensity signals. The computer code first normalizes the signals based on the following formula:

$$
\begin{cases}I_{n}(t)=0 & \text { if } I(t) \leq T \\ I_{n}(t)=1 & \text { if } I(t) \geq T\end{cases}
$$

where $I_{n}(t)$ is the normalized light intensity; $I(t)$ is the original light intensity; and $T$ is a threshold value. $T$ is taken as the maximum value in signals from a gas-free liquid-solid suspension. Then a peak in the lower tip signal is used as a trigger to match a peak in the upper tip signal. The $\Delta \tau_{2}$ of these two peaks, shown in Figure 1, should be smaller than 0.018 second, since the detectable minimum bubble rise velocity is $8 \mathrm{~cm} / \mathrm{s}$. Also, the ratio of the width of peak $(\tau)$ in the upper tip signal to that in the lower tip signal is between 0.7 and 1 , based on a calibration. After the peaks are matched, the bubble rise velocity is: 
$U_{b}=\frac{\Delta L}{\Delta \tau_{2}}$

where $\Delta L$ is the vertical distance between the two measuring tips. The bubble chord length is then

$l=\tau U_{b}$

The computer code was used to analyze the signal when the probe was placed in a chain of bubbles. The result from the computer program matched well that from visualization.

The computer code was then used to analyze the signals obtained from slurry bubble columns. Figure 2 shows a typical signal obtained in a slurry bubble column. The probability density function of the bubble chord length is shown in Figure 3. It can be seen from Figure 3 that the bubble size distribution at the ambient pressure was wide, with a maximum bubble chord length of $6 \mathrm{~cm}$ which was more than half of the column size $(10.16 \mathrm{~cm})$. This result proves that the bubble column is in the slugging regime at a gas velocity of $34.6 \mathrm{~cm} / \mathrm{s}$ and at $0.1 \mathrm{MPa}$ pressure.

The computer code will be used to analyze the bubble size distribution and operating regime in slurry bubble columns under high-pressure and high-gas velocity conditions.

\section{Effect of Pressure on the Gas Holdup of Slurry Bubble Column}

With the probe system developed during the past two quarters, attention has shifted to investigating the effect of pressure on the hydrodynamics, including gas holdup and bubble size distribution, in high-pressure slurry bubble columns at high gas velocities.

The measurement of the gas holdup is based on the bed collapse technique described in the quarterly report of July 1997 . Efforts were made to further improve that technique, which involves the simultaneous shutoff of both the inlet and outlet of the slurry bubble column after it reaches a steady state. The dynamic pressure gradient signal was recorded with a computer data acquisition system during the entire bed collapse process. The ratio of solids holdup to liquid holdup, $K$, in a slurry bubble column at steady state can be calculated from the dynamic pressure drop in the gas-free suspension stage:

$K=\frac{\varepsilon_{s}^{0}}{\varepsilon_{l}^{0}}=\frac{(\Delta P / \Delta z)_{d}^{0}}{\left(\rho_{s}-\rho_{l}\right) g-(\Delta P / \Delta z)_{d}^{0}}$

where $\varepsilon_{s}^{0}, \varepsilon_{l}^{0}$, and $(\Delta P / \Delta z)_{d}^{0}$ are the solids holdup, liquid holdup, and dynamic pressure gradient at the gas-free suspension stage, respectively. At a steady state, the gas holdup can be related to the dynamic pressure gradient, phase densities, and the constant $K$ by 


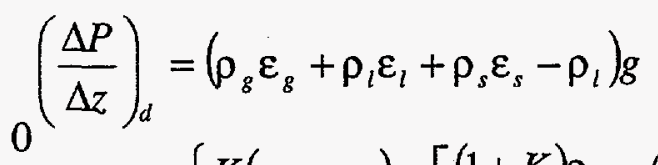

$$
\begin{aligned}
& =\left\{\frac{K\left(\rho_{s}-\rho_{l}\right)}{1+K}+\left[\frac{(1+K) \rho_{g}-\left(\rho_{l}+K \rho_{s}\right)}{1+K}\right] \varepsilon_{g}\right\} g
\end{aligned}
$$

where $\varepsilon_{s}, \varepsilon_{l}, \varepsilon_{g}$, and $(\Delta P / \Delta z)_{d}$ are the solids holdup, liquid holdup, gas holdup, and dynamic pressure gradient at the steady state, respectively. Substituting Eq.(4) into Eq.(5), the gas holdup at the steady state can be derived as

$$
\varepsilon_{g}=\frac{\left[(\Delta P / \Delta z)_{d}-(\Delta P / \Delta z)_{d}^{0}\right] / g}{\left(\rho_{g}-\rho_{l}\right)-(\Delta P / \Delta z)_{d}^{0} / g}
$$

Equation (6) was used to evaluate the gas holdup of high-pressure slurry bubble columns because of its two advantages. The solids density, $\rho_{s}$, cannot be easily be measured for porous particles in liquids, as hydrocarbon liquids can partially fill the pores of particles. Eq.(6) eliminates the particle density from the calculation. This technique can also determine if the particles in the column are completely suspended by comparing the dynamic pressure gradient at the gas-free suspension stage, $(\Delta P / \Delta z)_{d}^{0}$, obtained at different gas velocities. $(\Delta P / \Delta z)_{d}^{0}$ remains a constant when all the particles are suspended. In the literature, sampling of the liquid-solid mixture has been used for the same purpose. However, the sampling technique at high pressures is tedious and inconvenient to conduct. Also, the amount of liquid and particles cannot be maintained constant.

Figure 4 shows the gas holdup in a slurry bubble column with a solids concentration of $20 \mathrm{wt} \%$ at $28^{\circ} \mathrm{C}$ and various pressures. It can be seen that the gas holdup increases with an increase in pressure. The difference between this result and that obtained by sampling of liquid-solid mixture is negligible. 


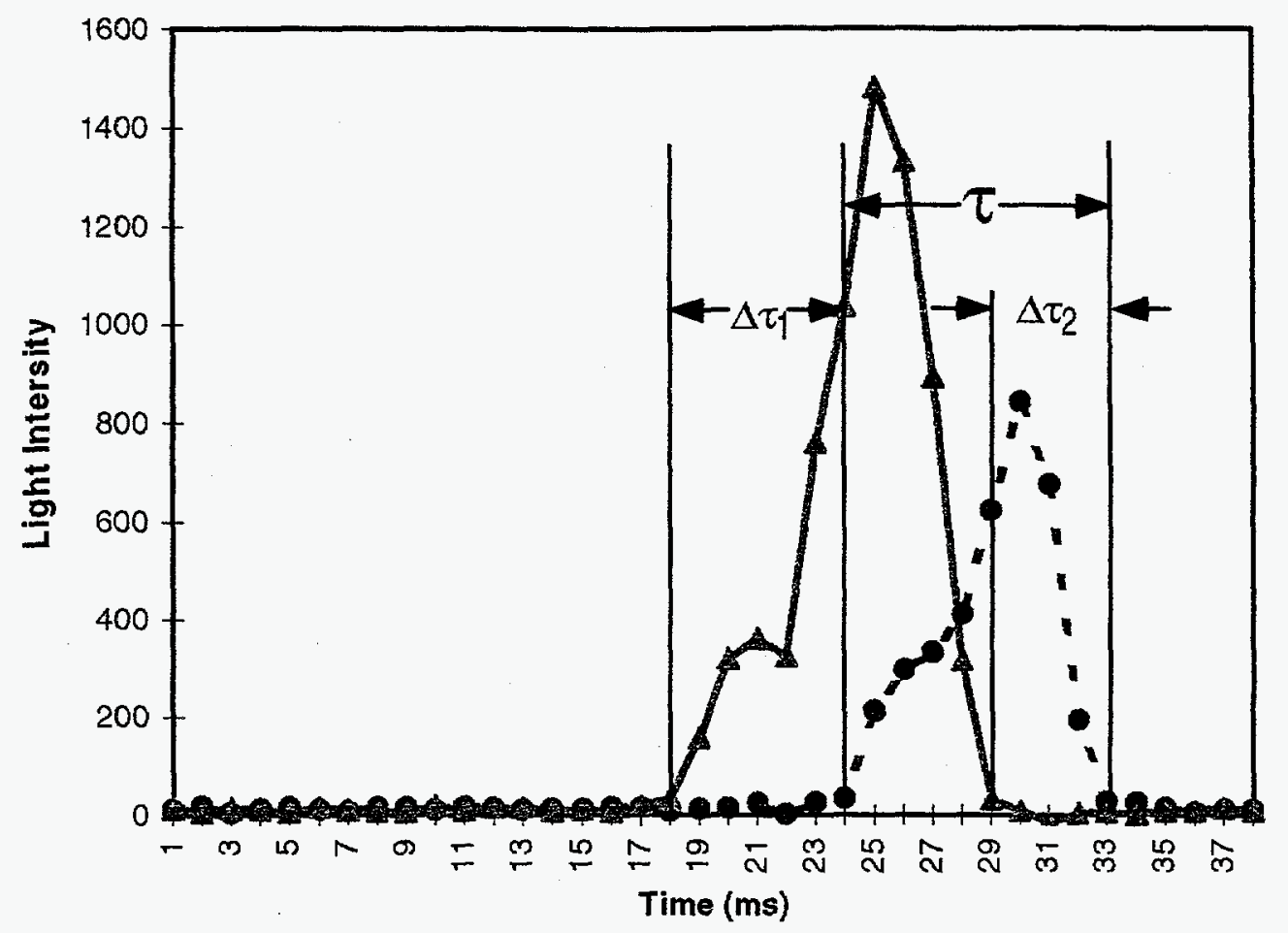

Figure 1. Characteristics and Notations of Peaks of Light Intensity Signals

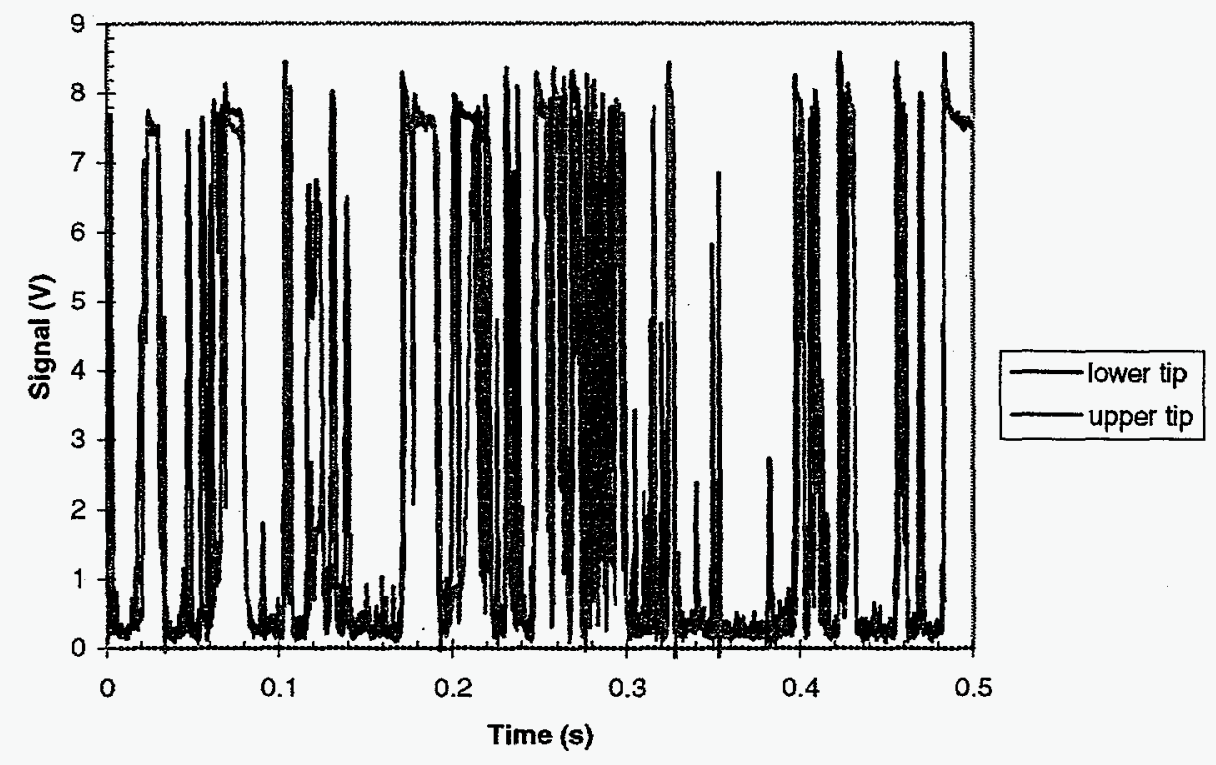

Figure 2. Typical Signals Obtained in Slurry Bubble Column 


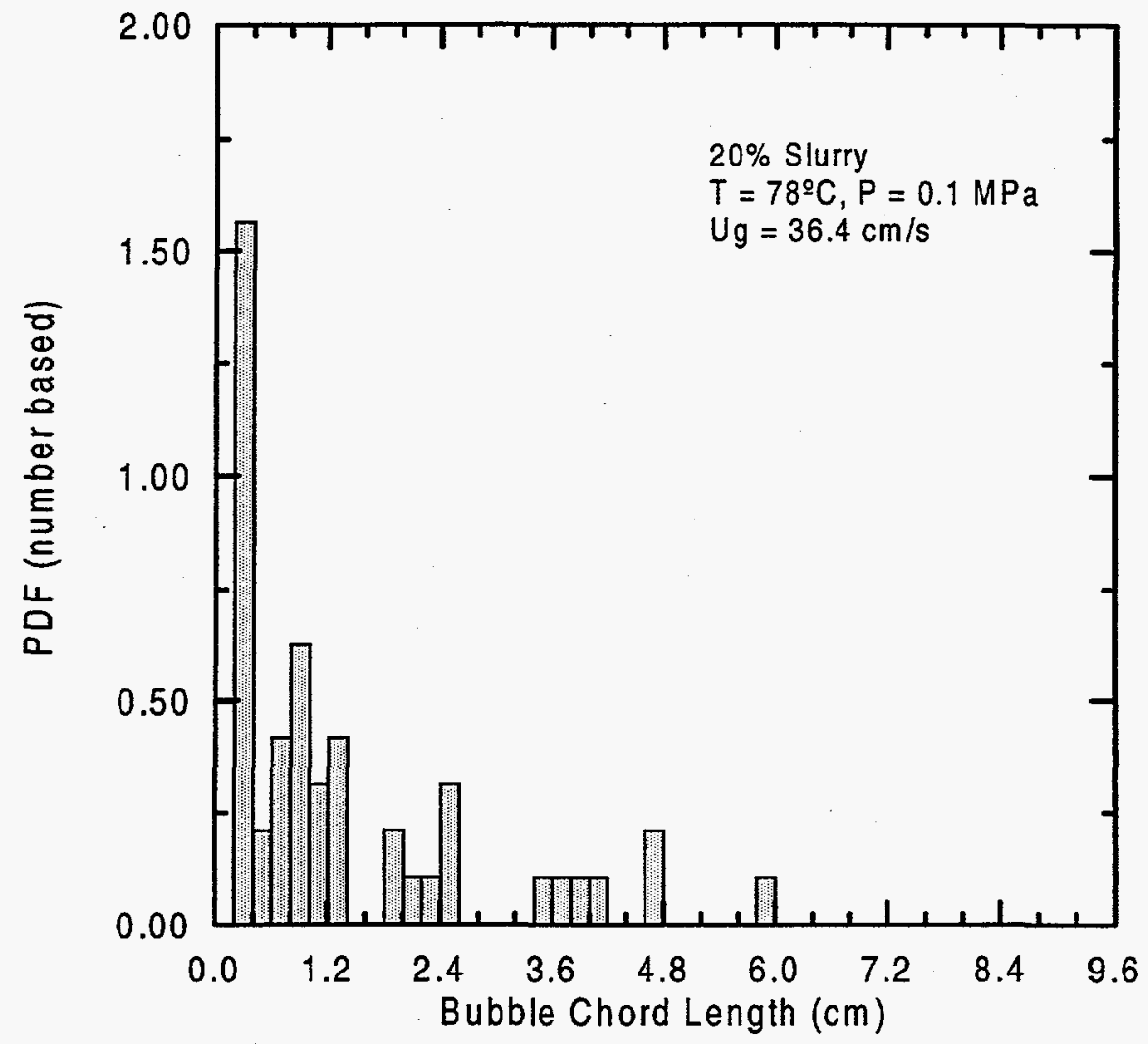

Figure 3. A Typical Bubble Chord Length Distribution from the Computer Code 


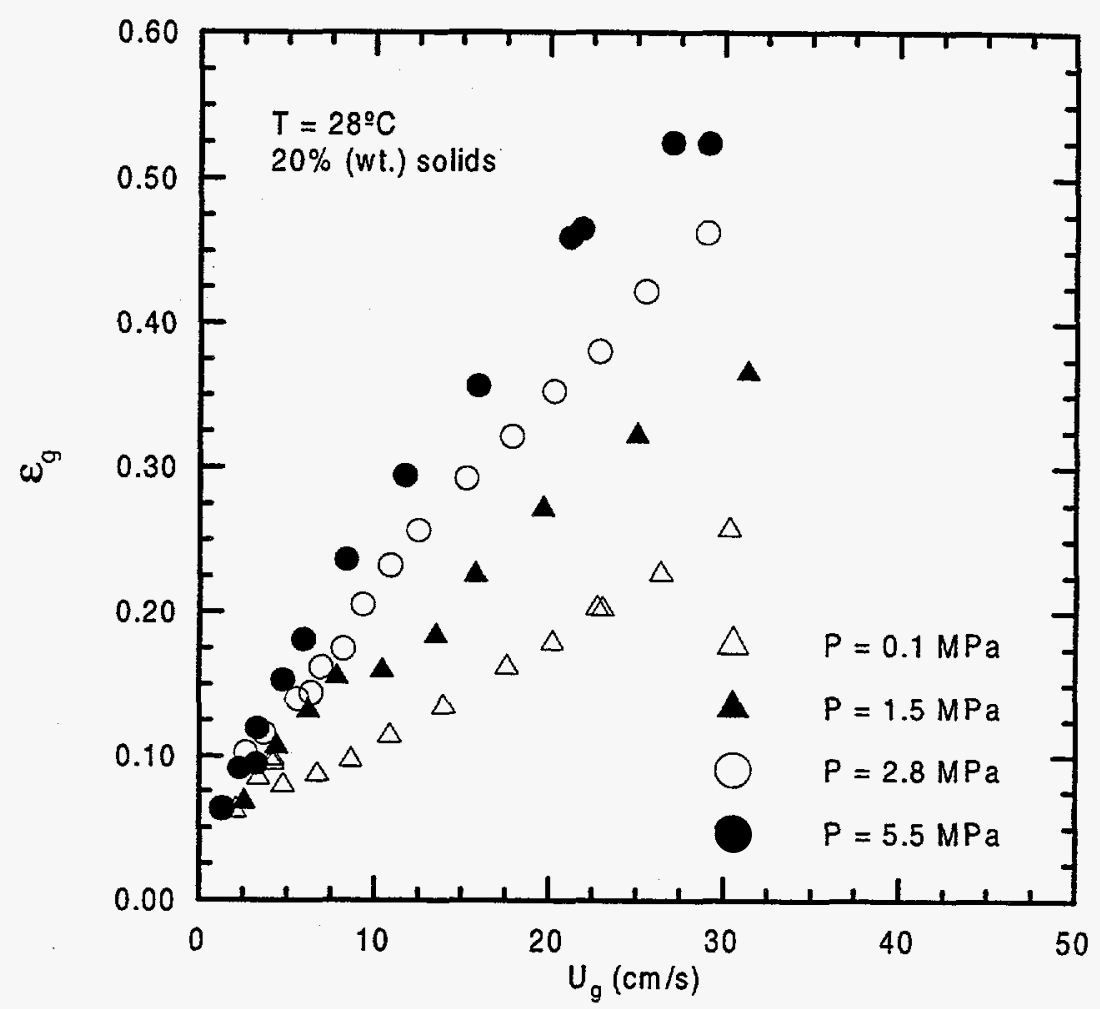

Figure 4. Gas Holdup in a Slurry Bubble Column at $28^{\circ} \mathrm{C}$ and Various Pressures 


\section{Washington University in St. Louis}

The following report from Washington University for the period contains these brief chapters:

Objectives for the Third Budget Year

Outline of Accomplishments

1. Turbulence Parameters in 18-in. Diameter Columns with and without Internals

2. Establishment of the Relationship between the Axial Dispersion Coefficient and Parameters of the Phenomenological Recycle with Cross Flow and Eddy Diffusion Model

3. Progress in Evaluation of the Momentum Balance Equation for Bubble Column Using CARPT and CT Measurements 


\section{ENGINEERING DEVELOPMENT OF SLURRY BUBBLE COLUMN REACTOR (SBCR) TECHNOLOGY}

Eleventh Quarterly Report

Budget Year 3: October 1 - December 31, 1997

Submitted to

Air Products and Chemicals, Inc.

Contract No.: DE-FC 2295 PC 95051

Chemical Reaction Engineering Laboratory

Chemical Engineering Department

Washington University in St. Louis 


\section{Objectives for the Third Budget Year}

The main goal of this subcontract from the Department of Energy via Air Products to the Chemical Reaction Engineering Laboratory (CREL) at Washington University is to study the fluid dynamics of slurry bubble columns and address issues related to scaleup and design. The objectives for the third budget year (October 1, 1997 -September 30,1998) were set as follows:

- Further development of phenomenological models for liquid and gas.

- Testing of the models against available data from the LaPorte AFDU.

- Evaluation of turbulent parameters in 18-in.-diameter columns with and without internals using collected CARPT data in these columns.

- Development of relationships between fundamental and simpler practical models for industrial use.

- Further improvement in fundamental computational fluid dynamics models and testing of the models against the CARPT/CT data.

- Preliminary assessment of differences in gas-liquid and gas-liquid-solid systems.

- Testing of the effect of the distributor on flow patterns.

In this report, the research progress and achievements accomplished in the eleventh quarter (October 1 - December 31, 1997) are discussed.

\section{Outline of Accomplishments}

\section{- Turbulence Parameters in 18-in. Diameter Columns with and without Internals}

The turbulence parameters (normal and shear stresses and kinetic energy) were evaluated from Computer Automated Radioactive Particle Tracking (CARPT) experiments performed at 2,5 and $10 \mathrm{~cm} / \mathrm{s}$ superficial gas velocities. These experiments were conducted with the air-drakeoil system in a 44.0-cm (18-in.) diameter column with and without internals. The internals consisted of 16 tubes of 1-in. diameter, which simulate the heat exchanger in the 18-in. diameter column used in the AFDU at LaPorte, Texas. A perforated plate distributor with hole diameter equal to $0.77 \mathrm{~mm}$ and an open area equal to $0.076 \%$ was used.

The results and comparison between the parameters obtained are reported and discussed. 
- Establishment of the Relationship between the Axial Dispersion Coefficient and Parameters of the Phenomenological Recycle with Cross Flow and Eddy Diffusion Model

A Taylor-type analysis of the two-dimensional convection-diffusion model for liquid mixing in a bubble column (which was developed and reported in the seventh and eighth quarterly reports) was performed to establish a relationship between the axial dispersion coefficient and the parameters of this new phenomenologically based model. While the recycle with the cross-flow model describes the phenomena that contribute to liquid mixing in a bubble column more reasonably than the axial dispersion model (ADM), the existence of only one parameter (the axial dispersion coefficient) renders the ADM still attractive to many. Therefore, we have developed a procedure to estimate the axial dispersion coefficient from the parameters of the phenomenologically more correct model.

\section{- Progress in Evaluation of the Momentum Balance Equation for Bubble Columns Using CARPT and CT Measurements}

It was reported in the $10^{\text {th }}$ quarterly report that the addition of the turbulent drag force to the radial momentum balance improved the agreement between the R.H.S. and L.H.S. of the balance for the case of high superficial gas velocity $(12 \mathrm{~cm} / \mathrm{s}$ in 14-cm diameter column). However, for the cases of low superficial gas velocity $(4.8 \mathrm{~cm} / \mathrm{s})$ in the $14-$ and $19-\mathrm{cm}$ diameter columns, the agreement between the R.H.S and L.H.S. of the radial momentum balance deteriorated with the addition of the turbulent drag force.

In this work, possible sources of the observed discrepancies are evaluated and discussed. Additional investigations were also conducted to detect the possible sources of error related to the assumption of fully developed flow and variability in determination of the Reynolds stress and gas holdup profiles, as well as the uncertainty in estimation of the gas velocity profile. 


\section{TABLE OF CONTENTS}

No.

Page No.

Objectives for the Third Budget Year

Outline of Accomplishments

ii

1. Turbulence Parameters in 18-in. Diameter Columns with and without Internals

1.1 Outline of the Experiments 1

1.2 Experimental Results and Discussions 2

1.2.1 Turbulent Parameters in the Column without Internals 2

1.2.2 Turbulent Parameters in the Column with Internals 2

1.2.3 Comparison of the Turbulent Stresses in the Columns with and without Internals

\subsection{References}

2. Establishment of the Relationship between the Axial Dispersion Coefficient and Parameters of the Phenomenological Recycle With Cross Flow and Eddy Diffusion Model

2.1 Two-Dimensional Convection-Diffusion Model for Liquid Mixing in Bubble Columns

2.2 Relationship between Axial Dispersion Coefficient and Parameters in the Phenomenological Recycle with Cross Flow and Eddy Diffusion Model

2.3 Nomenclature

$2.4 \quad$ References

3. Progress in Evaluation of the Momentum Balance Equation for Bubble Column Using CARPT and CT Measurements 
No.

3.1 Introduction

3.2 Discussion

3.3 Conclusion

3.4 Nomenclature

3.5 References
Page No.

22

23

25

25

26 


\section{Turbulence Parameters in 18-in. Diameter Columns with and without Internals}

In the $10^{\text {th }}$ quarterly report, we discussed the liquid recirculation velocities obtained by Computer Automated Radioactive Particle Tracking (CARPT) experiments and the cross-sectional gas holdup distribution obtained by Computer Tomography (CT) for the air-drakeoil system in 18-in. diameter columns with and without internals. Similarities and differences between liquid velocities in the two columns were discussed. In summary, the time averaged axial liquid velocity profiles in the column with internals exhibit trends similar to those obtained in the column without internals. However, as the superficial gas velocity increases, the velocity inversion point seems to move radially away from the wall in the column with internals, whereas in the column without internals the velocity inversion point occurs almost at the same radial position at all gas velocities. In the center of the column, the time-averaged axial velocity in the column with internals is somewhat larger than that obtained in the same column without internals. This difference could be caused by the poor statistics in the center of the column, which at that location is based on the smallest compartment for counting of the CARPT particle visits and causes increased and error in the estimated velocity. Therefore, in the first approximation (in the range of the gas superficial velocities studied, 2 to $10 \mathrm{~cm} / \mathrm{s}$ ), the internals do not seem to notably affect liquid recirculation. However, in the column with internals, the flow becomes developed at a relatively longer distance from the distributor compared to that in the column without internals.

In this section, the turbulence parameters (normal and shear stresses and kinetic energy) are evaluated in the same column operated with and without internals. The comparison between the obtained parameters is discussed.

\subsection{Outline of the Experiments}

The experimental setup and conditions were similar to those reported in the last quarterly report (see Figure 1.1). The column was made of Plexiglas with a diameter of 18 inches and a height of 8 feet $(\mathrm{L} / \mathrm{D}=5.3)$. The distributor used was a perforated plate with holes $0.77 \mathrm{~mm}$ in diameter and an open area of $0.076 \%$. The internals were composed of two bundles of 1-in. aluminum tubes. Each bundle had eight equally distributed tubes. The configuration of the internals simulated the heat exchanger tubes in the 18-in. diameter slurry bubble column reactor used in LaPorte, Texas. The radioactive particle used as tracer was Sc 46 , with activity of about 350 $\mu \mathrm{Ci}$. Thirty NaI scintillation detectors were employed in CARPT experiments. Data collection, at each gas superficial velocity, lasted about 40 hours in order to obtain good statistical results. The experiments were conducted at the gas superficial velocities of 2,5 and $10 \mathrm{~cm} / \mathrm{s}$ for the same column with and without internals. The system used was air-drakeoil (Drakeol ${ }^{\circledR} 10$, Van Waters \& Rogers Inc.).

\subsection{Experimental Results and Discussion}

\subsubsection{Turbulent Parameters in the Column without Internals}

Figures 1.2(a), (b) and (c) show the time-averaged shear stress and radial and axial normal stresses in the column without internals. It should be noted that the plots were obtained by averaging values over the developed flow region, which occupied the column between the 
heights of 30 and $180 \mathrm{~cm}$ from the distributor. The stresses increased with superficial gas velocity, as expected. The trends were similar to those obtained in the air-water system and in the smaller diameter columns. The magnitude of the radial normal stress was about half of that of the axial normal stress, while the magnitude of the shear stress was much smaller than that of normal stresses. The figures also show that at low superficial gas velocities $(2$ and $5 \mathrm{~cm} / \mathrm{s}$ ), the axial normal stress was slightly larger near the center and near the wall, while at high gas velocity $(10 \mathrm{~cm} / \mathrm{s})$, the axial normal stress decreased with decreasing distance to the wall, except at the closest point to the wall. This uncertainty is caused by lack of data near the wall. The magnitude of the radial normal stress at all three gas velocities slightly increased from the center to the wall. On the other hand, the shear stresses showed a maximum value near the dimensionless radius $(\mathrm{r} / \mathrm{R})$ of $0.5-0.6$ and almost zero near the center and near the wall of the column. All of these observations are similar to those obtained in the same size column for the air-water system.

Figure 1.3 shows the turbulent kinetic energy in the 18-in. diameter column for air-water and airdrakeoil systems and in the 6-in. diameter column for the air-water system. It is obvious that the turbulent kinetic energy was about the same for air-water and air-drakeoil systems, except in the region near the wall, which could also be due to inadequate statistics, causing the error in time averaging. Turbulent kinetic energy was higher in the 18-in. column compared to that obtained in the 6-in. diameter column (the distributor used in the 6-in. column consisted of a hole size = $0.04 \mathrm{~cm}$ and an open area $=0.05 \%$ ).

\subsubsection{Turbulent Parameters in the Column with Internals}

Figures 1.4(a), (b) and (c) illustrate the time-averaged shear stress and radial and axial normal stresses. As mentioned in the $10^{\text {th }}$ quarterly report, since a larger distance was needed to develop the flow in the column with internals, only the top half of the column was considered to be the developed region, and averaging was performed only in this part of the column. The trends of axial and radial normal stresses were quite similar to those obtained in the column without internals. The stresses increased with gas superficial velocities. However, at $2 \mathrm{~cm} / \mathrm{s}$ gas superficial velocity, the axial normal stress increased significantly near the wall, and was even higher than the axial normal stress at $5 \mathrm{~cm} / \mathrm{s}$ gas superficial velocity. The reason for this is not clear. For the shear stress, negative values were observed at gas superficial gas velocities of 2 and $5 \mathrm{~cm} / \mathrm{s}$ near the wall, even in the time-averaged sense.

\subsubsection{Comparison of Turbulent Stresses in the Columns with and without Internals}

Figures 1.5, 1.6, and 1.7 compare the stresses in the columns with and without internals at superficial gas velocities of 2,5 and $10 \mathrm{~cm} / \mathrm{s}$, respectively. Figure 1.8 compares turbulent kinetic energy at $10 \mathrm{~cm} / \mathrm{s}$ gas superficial velocity, with and without internals. The magnitudes and the trends of the radial profiles of the turbulent stresses in the column with internals were quite similar to those obtained in the column without internals, except near the wall of the column. These differences in the region near the wall were likely caused by the error associated with the reconstruction of the instantaneous particle positions and by lack of data. The magnitude of the radial normal stress in the column without internals was slightly higher than that in the column with internals in the region between the column center and the wall, while a reverse trend was observed near the wall of the column. However, the shear stress in the column with internals was lower than that in the column without internals, indicating that the presence of the internals 
indeed reduces the radial length scales of turbulence. This qualitatively verifies Degalessan's assumption for the LaPorte Alternative Fuels Development Unit reactor (Degalessan, 1997). Of course, comparison of eddy diffusivities in the columns with and without internals is needed. Since, evaluation of eddy diffusivities for CARPT data is a very lengthy and time-consuming process, it will be accomplished during the next phase of the work and cannot be reported here.

In summary, the presence of internals does not notably change the gross time-averaged flow pattern or turbulent stresses in the fully developed region of the column, especially at high superficial gas velocity, when the column is in the churn turbulent regime. Slightly larger differences are observed at the center and near the wall of the column in some cases, which might result from the poor statistics of particle occurrence in these regions.

\subsection{References}

1. Degaleesan, S., "Fluid Dynamic Measurements and Modeling of Liquid Mixing in Bubble Columns," D. Sc. Thesis, Washington University in St. Louis, 1997. 


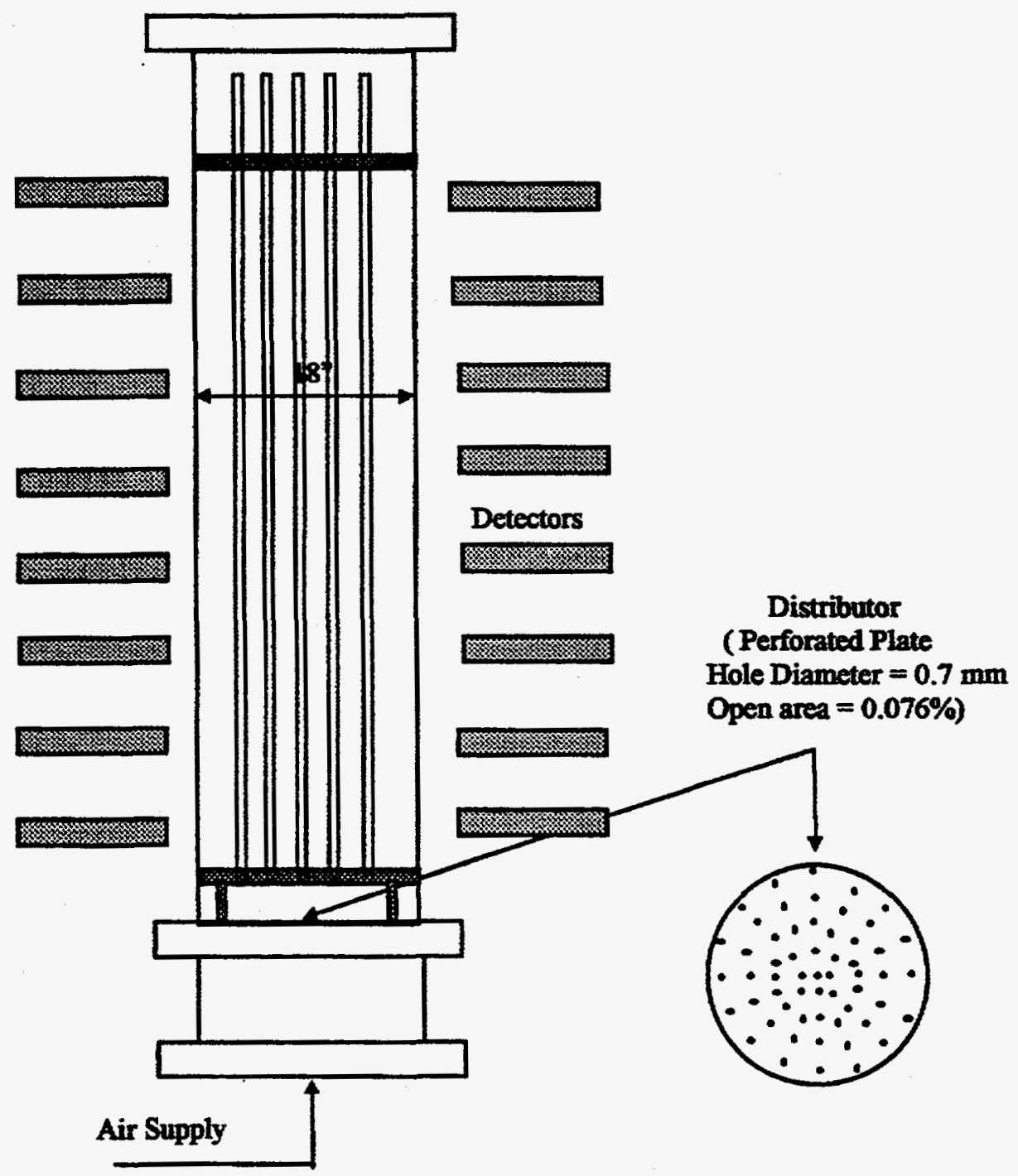

Figure 1.1(a). Experimental set-up for the $18^{\prime \prime}$ column CARPT nuns 


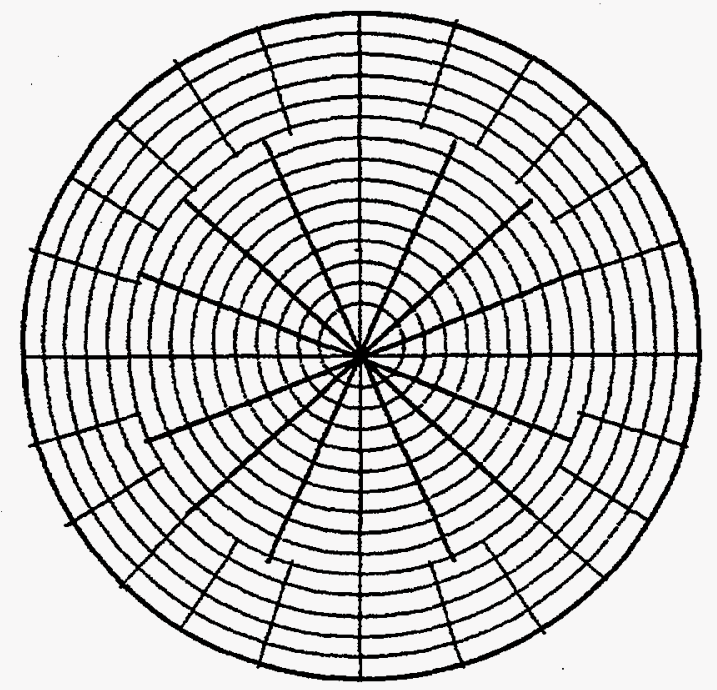

\begin{tabular}{l} 
Open area $=0.076 \%$ \\
301 holes of $0.7 \mathrm{~mm}$ \\
in diameter on 14 \\
concentric circular \\
rings at $1.5 \mathrm{~cm}$ apart. \\
\hline
\end{tabular}

Figure 1.1(b). Perforated plate distributors used in the experiments

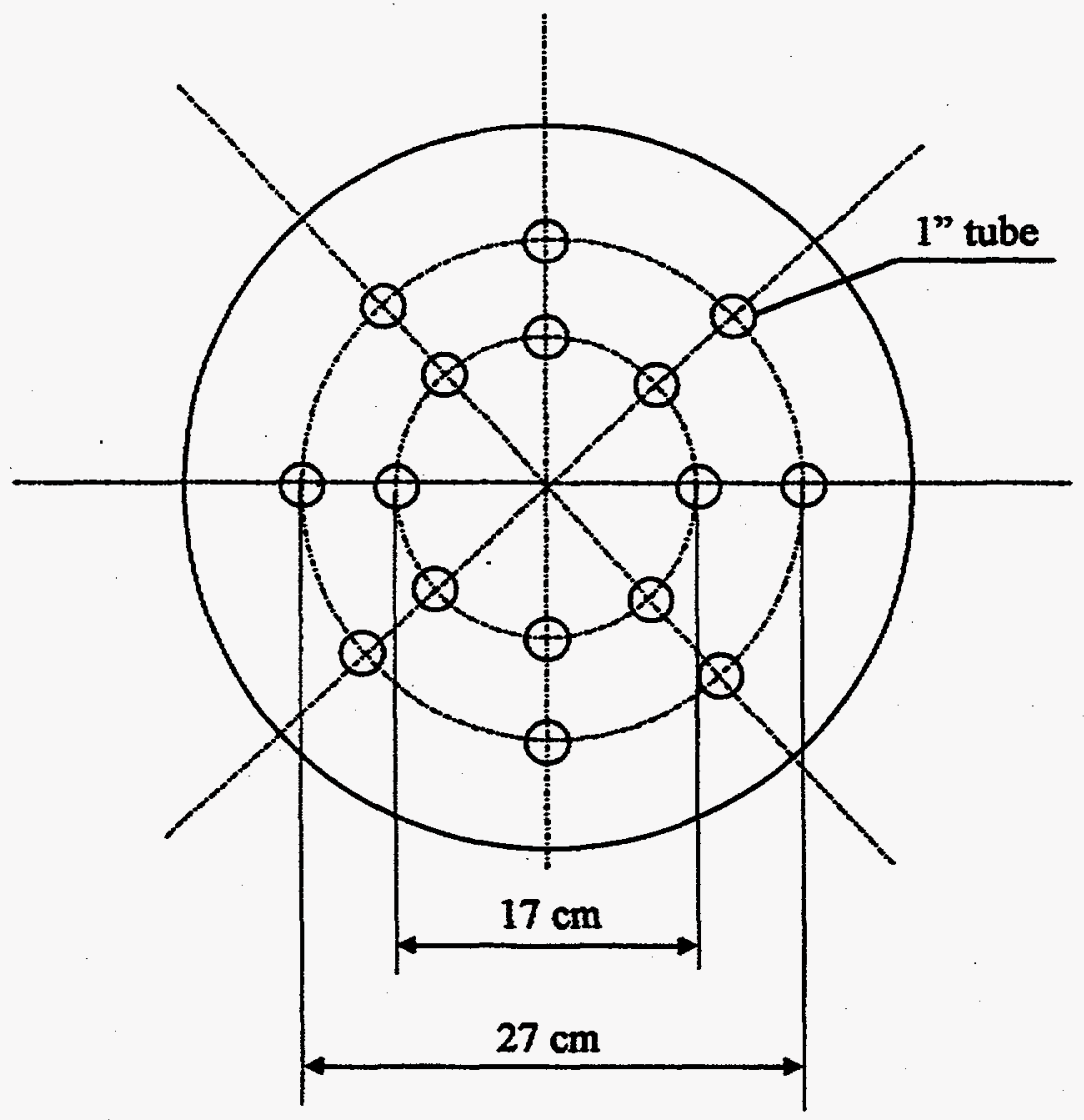

Figure 1.1(c). Configuration of the internals 


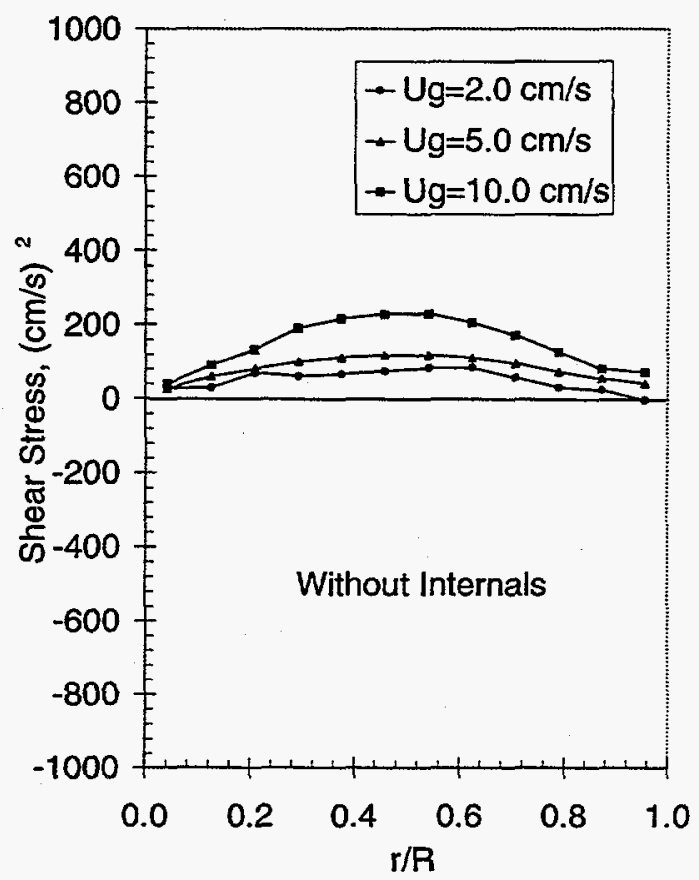

(a)

(b)

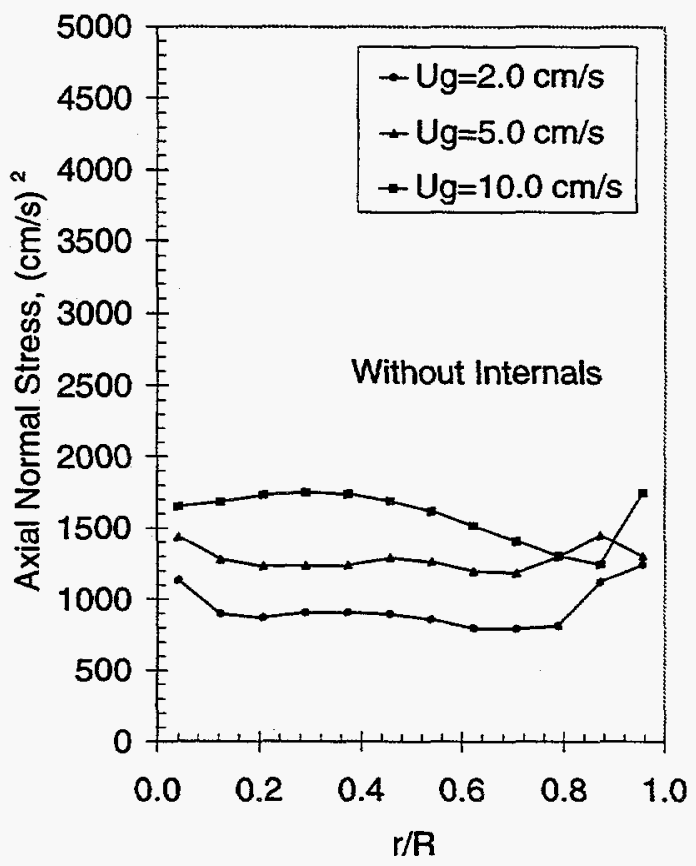

(c)

Figure 1.2 Turbulent Parameters in the 18-in. Column without Internals Using the Air-Drakeoil System 


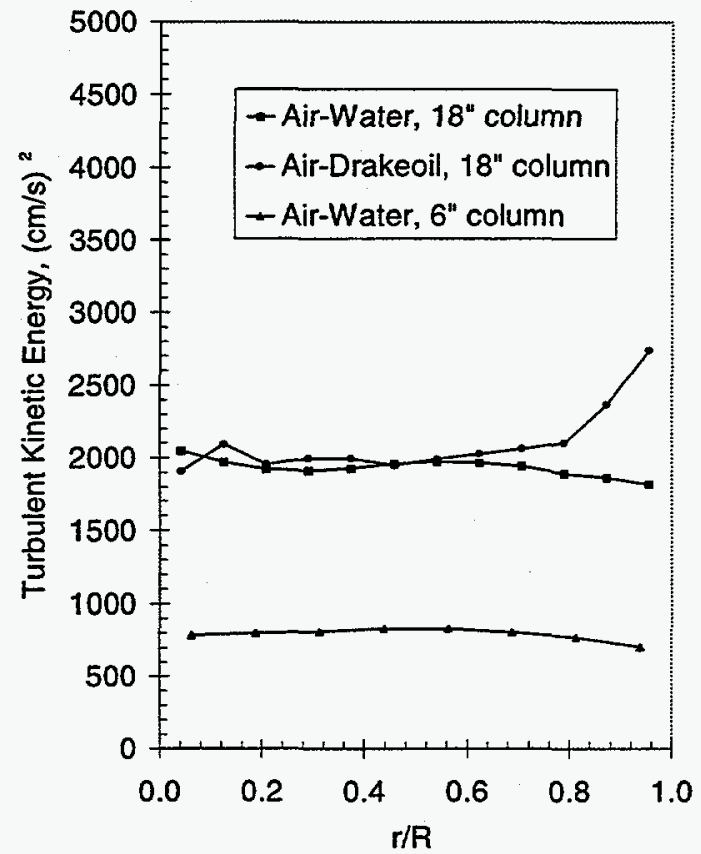

Figure 1.3 Turbulent Kinetic Energy in 18-in. and 6-in. Diameter Columns (The distributors are: 6-in. diameter column: hole size $=0.04 \mathrm{~cm}$, open area $=0.05 \%$; 18in. diameter column: hole size $=0.077 \mathrm{~cm}$, open area $=0.076 \%$ ) 


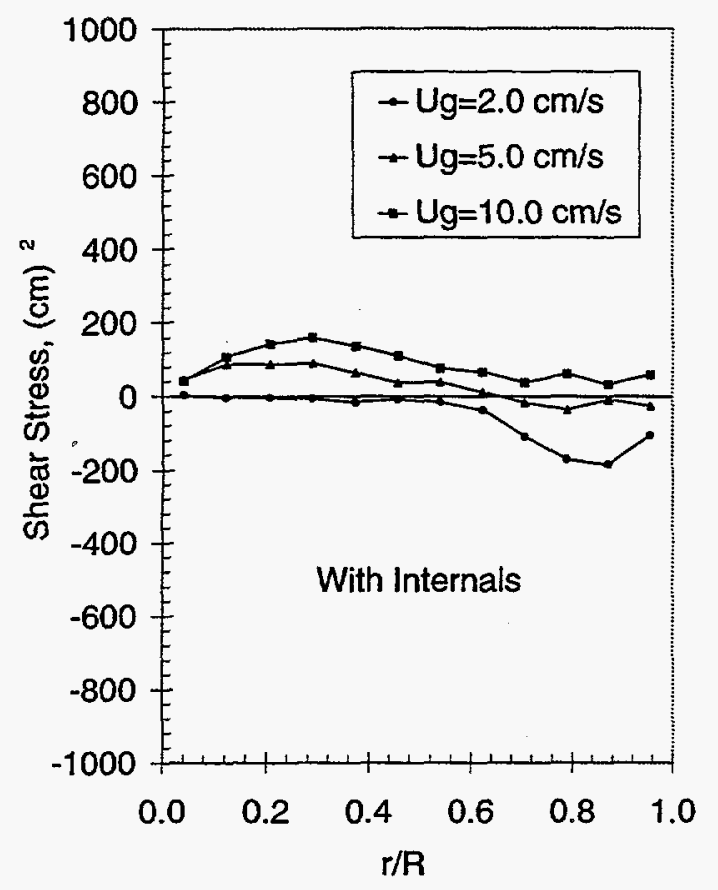

(a)

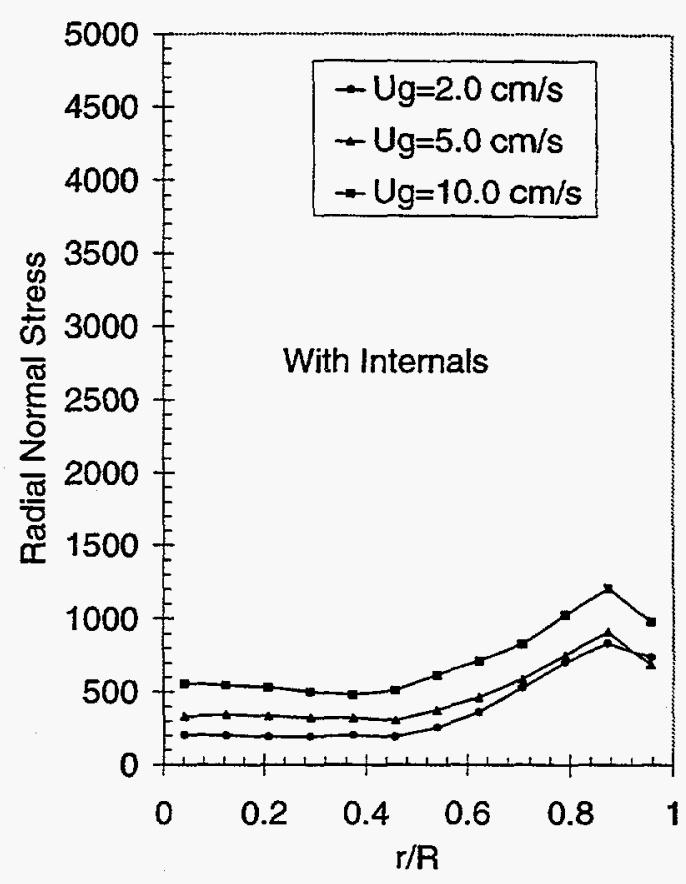

(b)

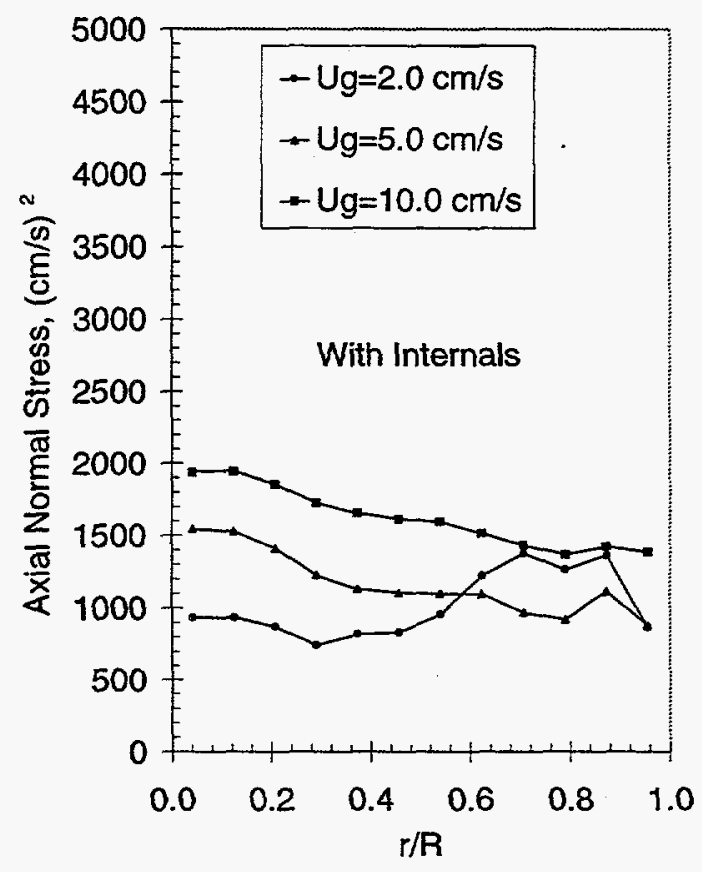

(c)

Figure 1.4 Turbulent Parameters in the 18-in. Column with Internals Using the Air-Drakeoil System 


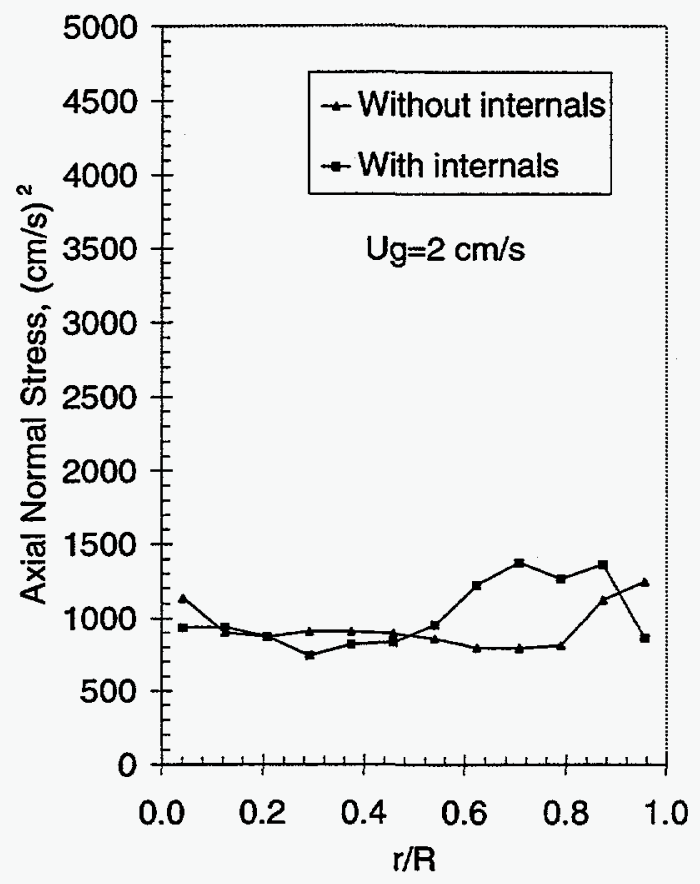

(a)

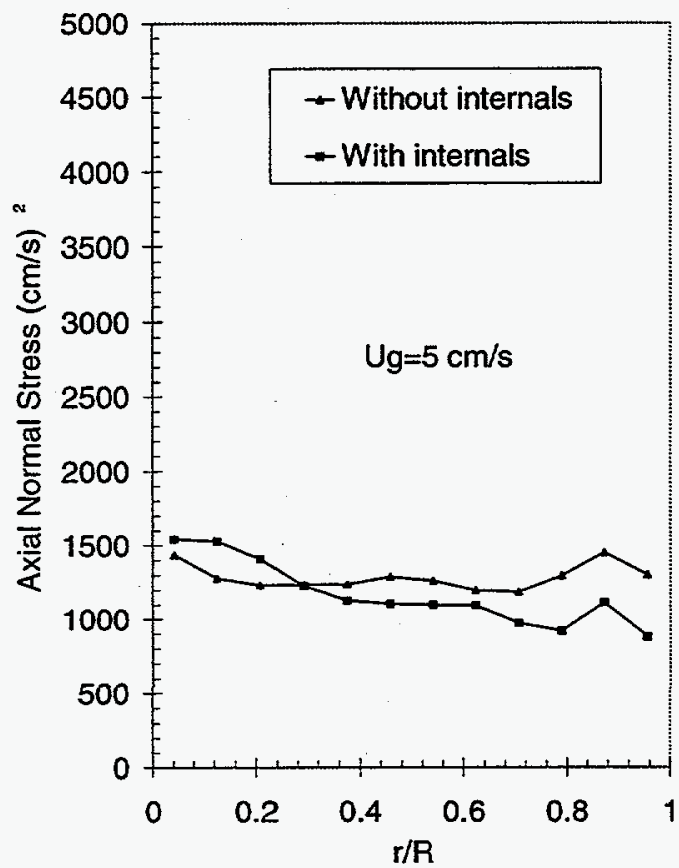

(b)

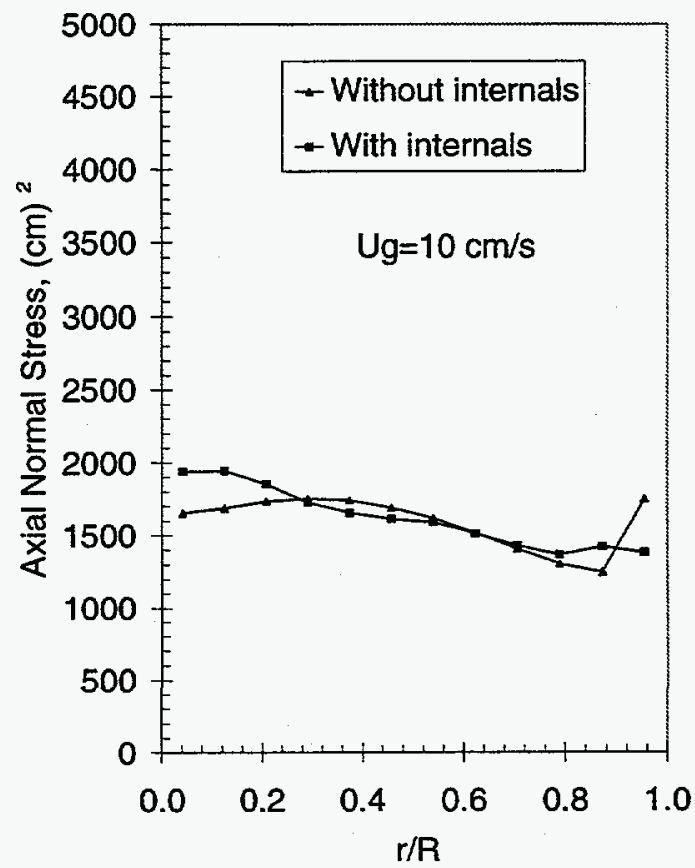

(c)

Figure 1.5 Comparison of Axial Normal Stresses in the Columns with and without Internals Using the Air-Drakeoil System 


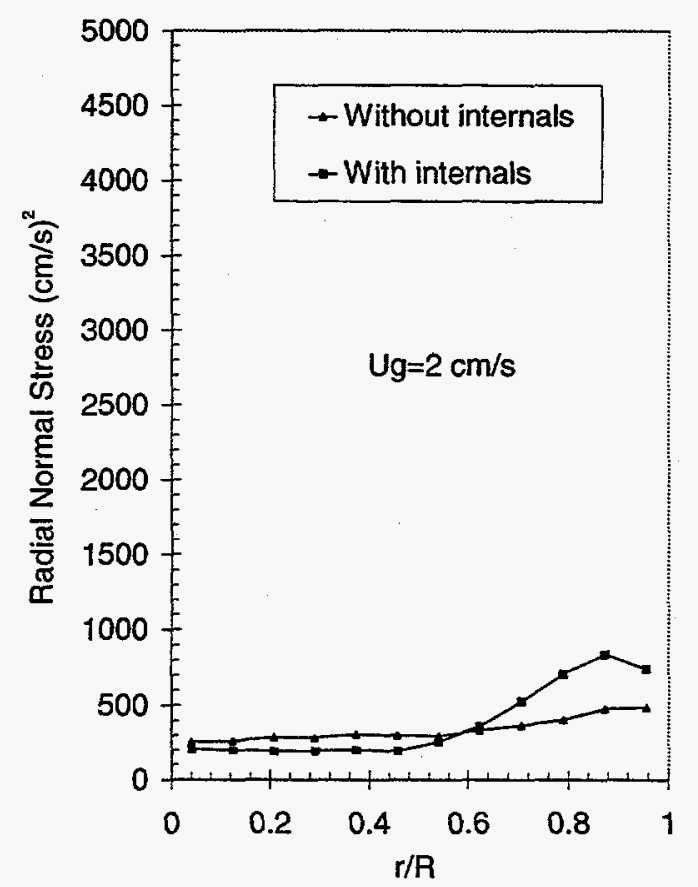

(a)

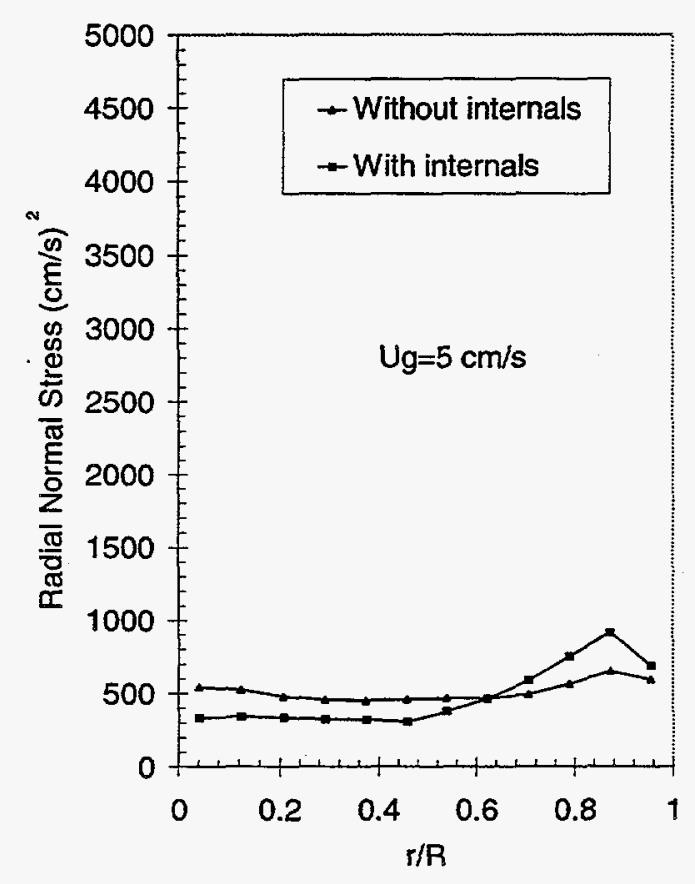

(b)

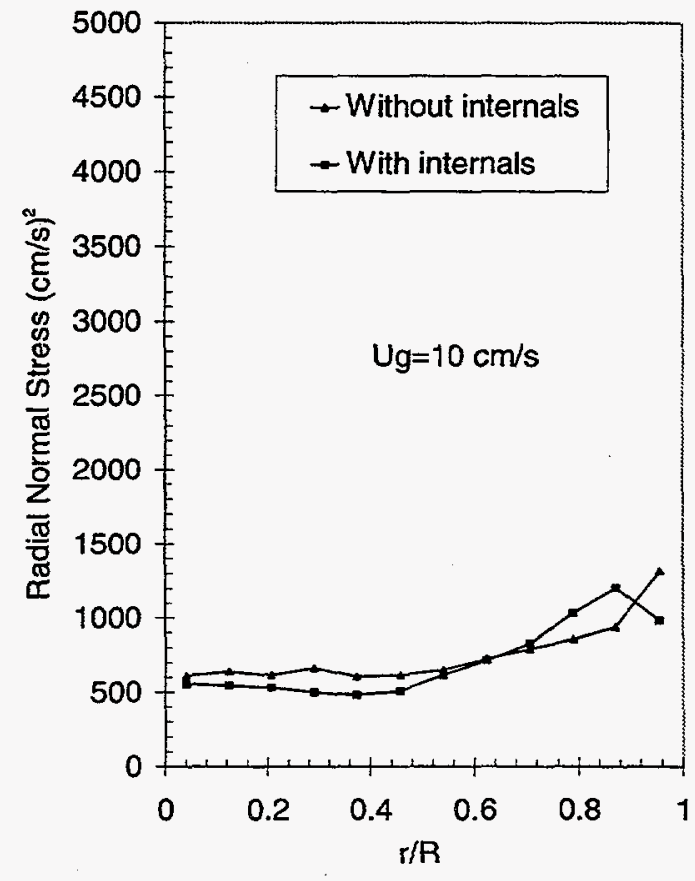

(c)

Figure 1.6 Comparison of the Radial Normal Stresses in the Columns with and without Internals Using the Air-Drakeoil System 


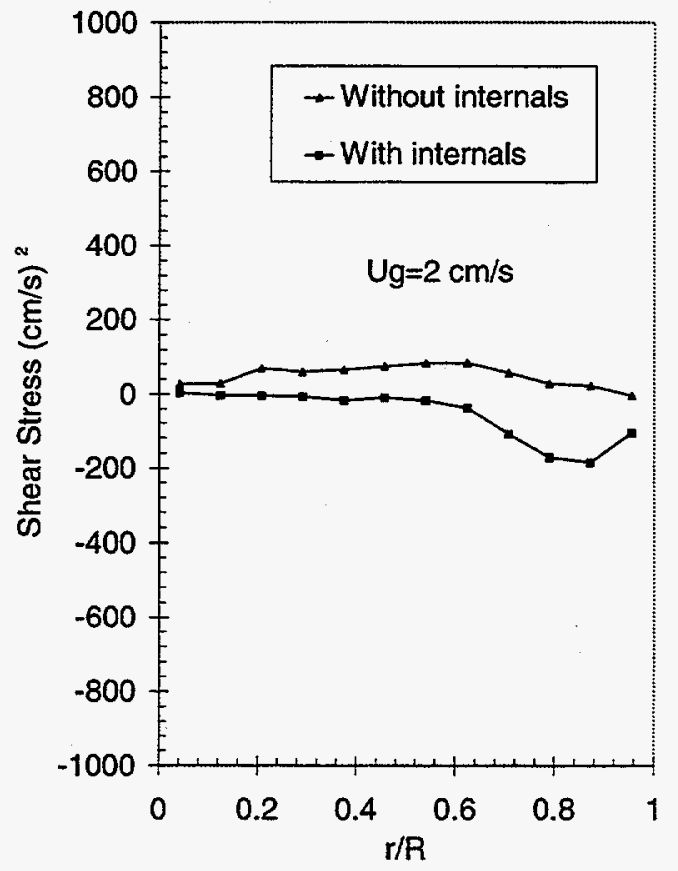

(a)

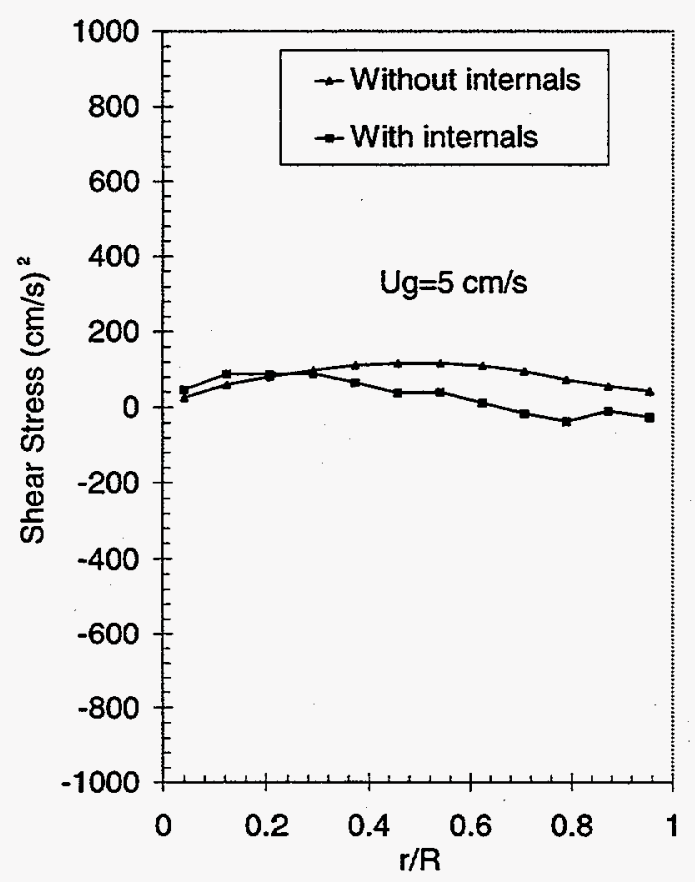

(b)

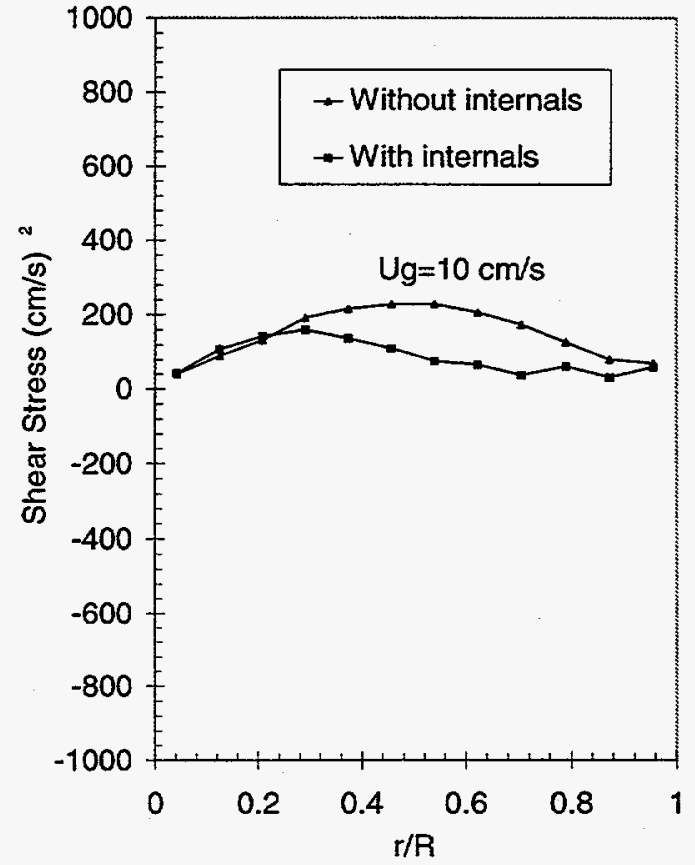

(c)

Figure 1.7 Comparison of the Shear Stresses in the Column with and without Internals Using the Air-Drakeoil System 


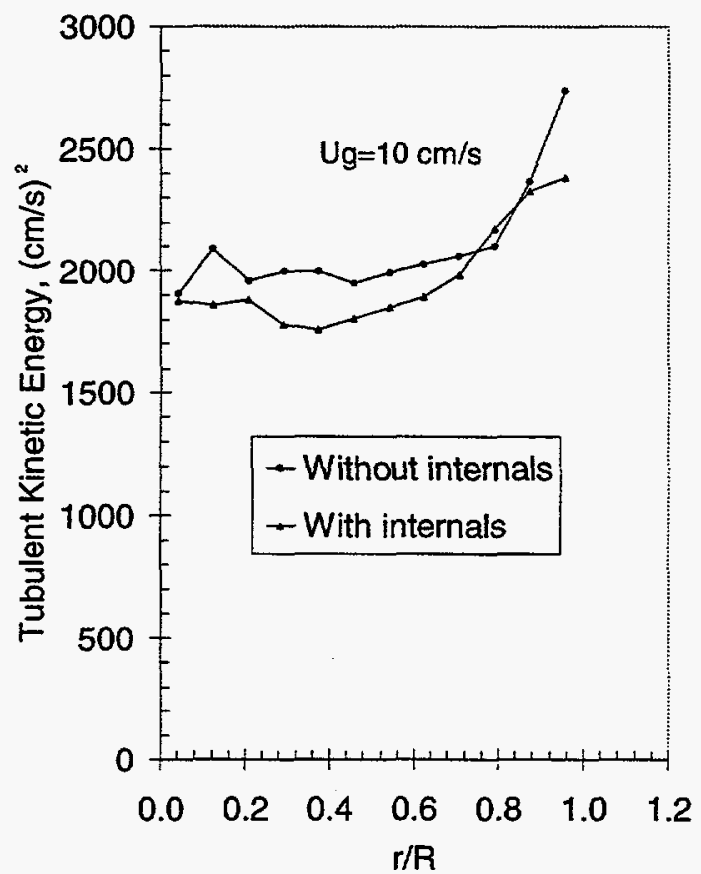

Figure 1.8 Comparison of the Turbulent Kinetic Energy at Gas Superficial Velocity of $10 \mathrm{~cm} / \mathrm{s}$ in the Column with and without Internals Using the Air-Drakeoil System

\section{Establishment of the Relationship between the Axial Dispersion Coefficient and Parameters of the Phenomenological Recycle with Cross-Flow and Eddy Diffusion Model}

A Taylor-type analysis of the two-dimensional convection-diffusion model for liquid mixing in a bubble column (which was developed and reported in the seventh and eighth quarterly reports) was performed to establish a relationship between the axial dispersion coefficient and the parameters of this new phenomenologically based model. While the developed recycle with cross flow model describes the phenomena that contribute to liquid mixing in bubble columns more reasonably than the axial dispersion model (ADM), the existence of only one parameter (the axial dispersion coefficient) makes the ADM still attractive to many. Therefore, we have developed a procedure to estimate the axial dispersion coefficient from the parameters of the phenomenologically more correct model. For clarity, we first reintroduced the fundamental convective-diffusion model and showed how to relate its parameters to the ADM.

\subsection{Two-Dimensional Convection-Diffusion Model for Liquid Mixing in Bubble Columns}

The fundamental two-fluid model mass balance equation for the local, instantaneous tracer species in phase $\mathrm{k}$ is as follows:

$$
\frac{\partial \rho_{k} C_{k}}{\partial t}+\nabla \cdot \rho_{k} C_{k} \vec{u}_{k}-D_{m} \nabla^{2} C_{k}=0
$$


with an interfacial jump condition for mass transfer across the interface:

$$
\sum_{k=1}^{2} \rho_{k} C_{k}\left[\vec{u}_{k}-\vec{u}_{k j}\right] \cdot \overrightarrow{\mathbf{n}}_{k}=0
$$

In the above equation, the phase density, $\rho_{\mathrm{k}}$, for incompressible flow such as in bubble columns can be considered to be constant. $D_{m}$ is the molecular diffusivity, which is small and will be ignored hereafter. Phasic or ensemble averaging of the above equation in an axisymmetric system, for an inert, non-volatile tracer, yields

$$
\begin{aligned}
& \frac{\partial}{\partial t}\left(\rho_{k} \varepsilon_{k}<C_{k}>^{x}\right)+\frac{\partial}{\partial z} \rho_{k}\left(\varepsilon_{k}<u_{z, k}>^{x}<C_{k}>^{x}+\varepsilon_{k}<u_{z, k} C_{k}^{\prime}>^{x}\right)+ \\
& \frac{1}{r} \frac{\partial}{\partial r} r \rho_{k}\left(\varepsilon_{k}<u_{r, k}>^{x}<C_{k}>^{x}+\varepsilon_{k}<u_{r, k}^{\prime} C_{k}^{\prime}>^{x}\right)=<\rho_{k} C_{k}\left(\vec{u}_{k}-\vec{u}_{k j}\right) \cdot \nabla X_{k}>
\end{aligned}
$$

Where \langle\rangle$^{\mathrm{x}}$ represents phasic averaging. The right-hand side of Equation 2.3 represents the term due to mass transfer across the interface, where $X_{k}$ is the phase function, defined as

$$
\begin{aligned}
& X_{k}(\vec{x}, t)=1 \text { if } \vec{x} \text { is in phase } k \text { at time } t \\
& =0 \text { otherwise }
\end{aligned}
$$

All other symbols are defined in the nomenclature. An additional source term to represent the reaction can be added to the right-hand side of the equation. For the current situation, considering a non-volatile inert liquid tracer, the right-hand side of Equation 2.3 is set to 0 . Since the model is primarily concerned with the liquid phase, the subscript $k=1$, denoting the liquid phase, is dropped. In addition, all symbols denoting averaging are dropped in order to simplify notation. All variables representing the fluid dynamic parameters and the tracer concentration denote the phase-averaged quantities.

The cross-correlation terms between the fluctuating velocity and tracer concentration are closed using a standard gradient diffusion model (Hinze 1995; Tennekes and Lumley 1971; Seinfeld 1986), as

$$
\left\langle u_{z}^{\prime} C^{\prime}\right\rangle=-D_{z r} \frac{\partial C}{\partial r}-D_{z z} \frac{\partial C}{\partial z}
$$

and

$$
\left\langle u_{r}^{\prime} C^{\prime}\right\rangle=-D_{\pi} \frac{\partial C}{\partial r}-D_{r z} \frac{\partial C}{\partial z}
$$

However, CARPT experiments show that the off-diagonal elements of the eddy diffusivity tensor are negligibly small. Hence,

$$
\mathrm{D}_{\mathrm{zr}}=\mathrm{D}_{\mathrm{rz}} \sim 0
$$


Therefore

$$
\begin{aligned}
& \left\langle u_{z}^{\prime} C^{\prime}\right\rangle=-D_{z z} \frac{\partial C}{\partial z} \\
& \left\langle u_{r}^{\prime} C^{\prime}\right\rangle=-D_{r} \frac{\partial C}{\partial r}
\end{aligned}
$$

In the above equations, $\mathrm{D}_{\mathrm{zz}}$ and $\mathrm{D}_{\mathrm{rr}}$ are the CARPT-measured axial and radial turbulent eddy diffusivity, respectively. Therefore, if one ignores the inter-phase exchange terms, the final form of the model equation for flow and mixing in the liquid phase is

$$
\frac{\partial(\varepsilon C)}{\partial t}+\frac{\partial}{\partial z}\left(\varepsilon u_{z} C\right)+\frac{1}{r} \frac{\partial}{\partial r}\left(r_{r} \mathrm{r}\right)=\frac{1}{r} \frac{\partial}{\partial r}\left(r_{\varepsilon D} \frac{\partial C}{\partial r}\right)+\frac{\partial}{\partial z}\left(\varepsilon D_{z z} \frac{\partial C}{\partial z}\right)
$$

Standard boundary conditions can now be used with zero flux at the wall and at the centerline of the column. For the case with continuous flow of liquid through the column, a zero gradient is assumed at the outlet, with injection of tracer at the inlet. Equation 2.10 represents the averaged balance equation for the non-volatile liquid species, and is a transient, two-dimensional convection-diffusion equation. The phase (or time) averaging that has been performed to arrive at this equation refers to any time interval, which may be small or large.

Multiphase flows in bubble columns are highly transient in nature. Hence, the length of the time interval considered in the averaging will affect the type of results obtained. Short-time averages involve averaging that is performed over a small time interval, large enough to smooth the variations across the interface, but small enough to capture some of the transient structures in the flow. These transient structures will vary in nature with the time interval of averaging. On the other hand, long-time averaging results in a statistically stationary flow field, which is steady in time, in terms of all the fluid dynamic variables.

Two factors are of concern here in determining the type of averaging for the above model equation. First, since the flow phenomena in bubble columns is highly turbulent and random in nature, a quantitative comparison of the fluid dynamic parameters, between model predictions and experimental measurements, can be made only with respect to the statistical properties of the flow field. This immediately implies that time or ensemble averaging is required. Second, since the current model is considered in a two-dimensional axisymmetric domain, the type of boundary conditions used (zero gradient at the centerline) will not permit the computation of physically realistic results describing the transient structures. A true transient behavior can only be represented in a fully three-dimensional flow model, which can capture the inherent vortical and spiraling motion of the flow in bubble columns.

For these reasons, we propose considering long-time averaging for the above model equation. The various averaged quantities in the above equation will hence refer to long-time averaged quantities and corresponding closure models (Equations 2.8 and 2.9). CARPT data for the long- 
time-averaged liquid velocities, $\mathrm{u}_{\mathrm{r}}$ and $\mathrm{u}_{\mathrm{z}}$, and turbulent diffusivities, $\mathrm{D}_{\mathrm{rr}}$ and $\mathrm{D}_{\mathrm{zz}}$, along with $\mathrm{CT}$ data for the time-averaged liquid holdup profile, can then be used as appropriate input parameters to the model.

\subsection{Relationship between Axial Dispersion Coefficient and Parameters in the Phenomenological Recycle with Cross Flow and Eddy Diffusion Model}

A Taylor-type analysis of the fundamental, two-dimensional, axisymmetric convection-diffusion equation for liquid mixing in bubble columns was performed to arrive at an expression for the effective axial dispersion coefficient in terms of the two dominant factors contributing to liquid backmixing, i.e., convective recirculation and turbulent eddy diffusion (axial and radial). This allowed us to quantify the contributions of these mechanisms to overall liquid mixing in the bubble column. This analysis is restricted to systems with low superficial liquid velocities, wherein the cross-sectional average liquid velocity relative to local liquid velocities is negligible. The treatment is based on a steady backmixing experiment in which gas and liquid are introduced at their respective flow rates co-currently from the bottom of the column, and a continuous stream of liquid tracer is introduced uniformly at the top of the column, as illustrated in Figure 2.1. For this analysis, the liquid flow rate through the column can be as low as possible, just sufficient to ensure an outflow of liquid that can carry the tracer. Due to liquid backmixing, a steady axial liquid tracer concentration profile is established in the column. This can be represented by the steady-state approximation of the transient, two-dimensional convection diffusion equation written as

$$
\frac{1}{r} \frac{\partial}{\partial r} \varepsilon(r) D_{r r}(r) r \frac{\partial C}{\partial r}=\varepsilon(r) u_{z}(r) \frac{\partial C}{\partial z}-\varepsilon(r) D_{z z}(r) \frac{\partial^{2} C}{\partial z^{2}}
$$

The above equation was written for the well-developed region of the flow in bubble columns, where the time-averaged axial liquid velocity is a function of radius only, and radial velocities are zero. End effects were ignored. This is applicable to bubble columns operating at large length-to-diameter ratios $(\geq 6)$. Based on the gathered experimental evidence, it was also assumed that the turbulent eddy diffusivities in the fully developed region were a function of radial position only. 


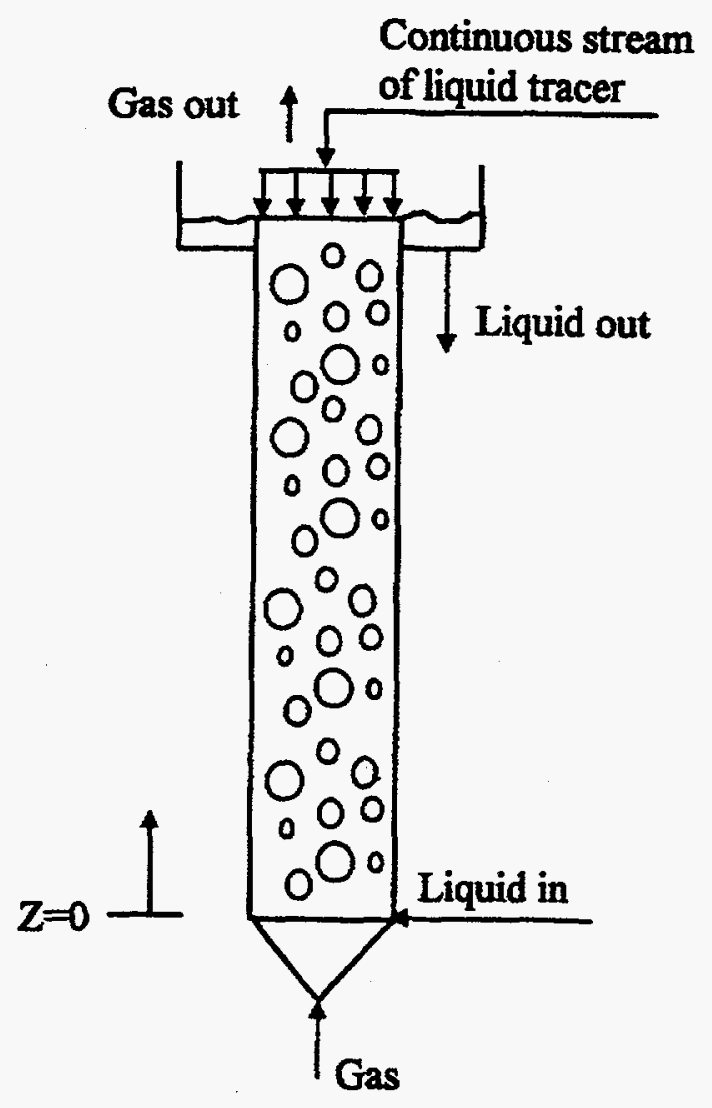

Figure 2.1. Steady Backmixing Liquid Tracer Experiment

The liquid tracer concentration $C(r, z)$ is now decomposed into two parts as

$$
\mathrm{C}(\mathrm{r}, \mathrm{z}) \equiv \overline{\mathrm{C}}(\mathrm{z})+\mathrm{C}^{\prime}(\mathrm{r})
$$

where $\bar{C}$ is a function of axial position only and $C^{\prime}(r)$ is dependent on radial position only. $\bar{C}$ is the cross-sectional average liquid concentration and, hence, is independent of radial position, $r$. $C^{\prime}$ represents the concentration variations around the cross-sectional mean, with a cross-sectional average of zero. Simulation results of the steady-state, two-dimensional model, shown in Figure 2.2 , indicate that $C^{\prime}$ is only a mild function of $\mathrm{z}$, which is negligible when compared to $\bar{C}$. Hence, Equation 2.12 is a good approximation of the actual liquid tracer concentration throughout the column. Equation 2.11 can now be rewritten as

$$
\frac{1}{r} \frac{\partial}{\partial r} \varepsilon(r) D_{r}(r) r \frac{\partial C^{\prime}(r)}{\partial r}=\varepsilon(r) u_{z}(r) \frac{\partial \bar{C}(z)}{\partial z}-\varepsilon(r) D_{z z}(r) \frac{\partial^{2} \bar{C}(z)}{\partial z^{2}}
$$


Experimental evidence from the literature (Ohki and Inoue, 1970; Myers, 1986) and simulation results (Figure 2.2) indicate an exponential dependence of the cross-sectional mean concentration $\bar{C}$ on axial position z, as shown by Equation (2.14):

$$
\bar{C}(z)=C_{0} \exp \left(k_{z} z\right)
$$

where $k_{z}$ is a constant. Therefore

$$
\frac{\partial^{2} \overline{\mathrm{C}}}{\partial \mathrm{z}^{2}}=\mathrm{k}_{\mathrm{z}} \frac{\partial \overline{\mathrm{C}}}{\partial \mathrm{z}}
$$

By substituting the above result into Equation (2.13), we get

$$
\frac{1}{r} \frac{\partial}{\partial r} \varepsilon(r) D_{r}(r) r \frac{\partial C^{\prime}(r)}{\partial r}=\frac{\partial \bar{C}(z)}{\partial z}\left[\varepsilon(r) u_{z}(r)-\varepsilon(r) D_{z z}(r) k_{z}\right]
$$

With a Taylor-type analysis (after double integration over r) having a symmetry condition at the center and zero flux at the wall, the following equations are obtained:

$$
C^{\prime}(r)=\frac{d \bar{C}(z)}{d z} I 2(r)
$$

where

$$
\mathrm{I} 2(\mathrm{r})=\int_{0}^{\mathrm{r}} \frac{\mathrm{I}\left(\mathrm{r}^{\prime}\right)}{\mathrm{r}^{\prime} \varepsilon\left(\mathrm{r}^{\prime}\right) \mathrm{D}_{\mathrm{rr}}\left(\mathrm{r}^{\prime}\right)} \mathrm{dr}
$$

and 

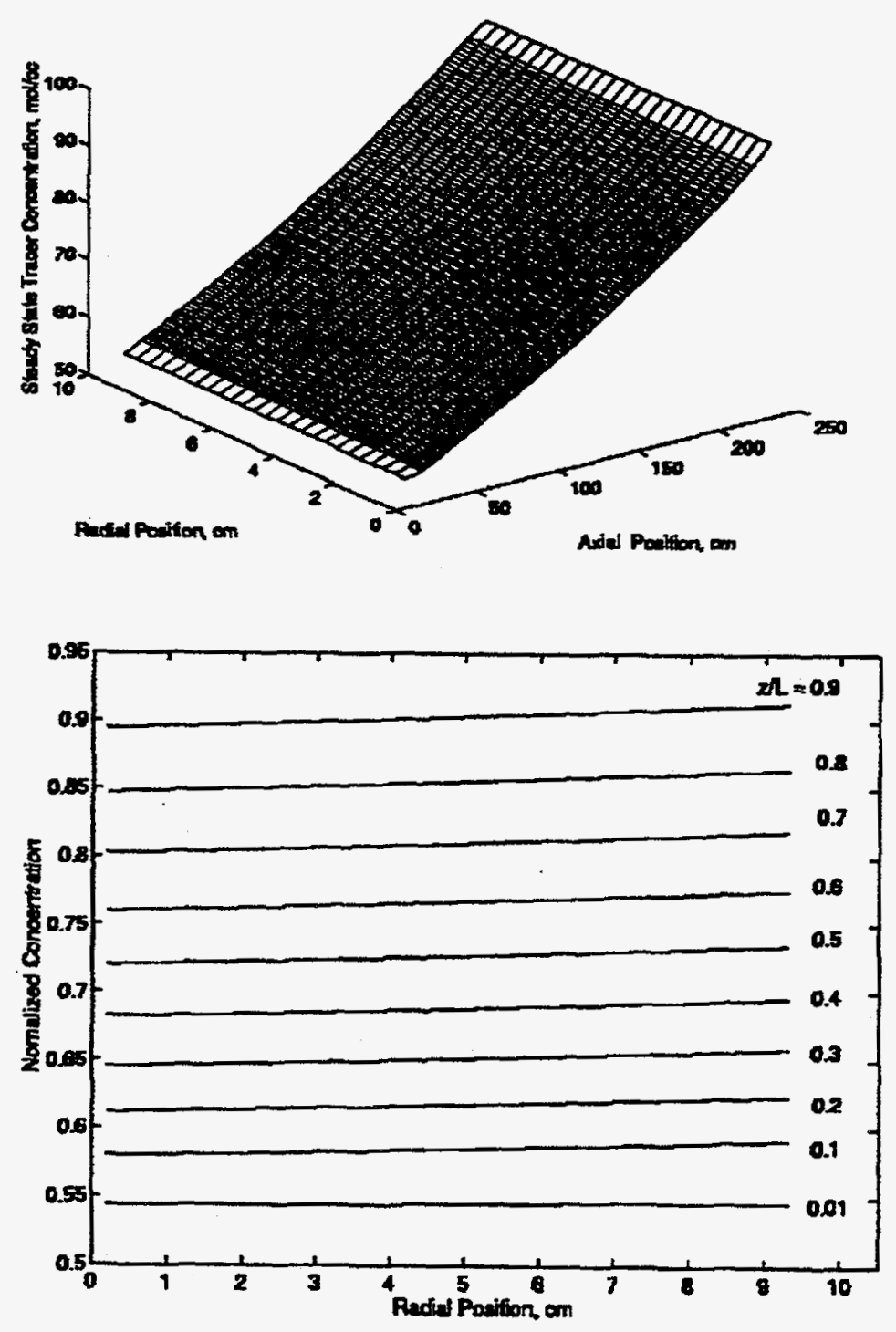

Figure 2.2. Simulation Results for the Steady State Two Dimensional Convection Diffusion Model 


$$
\int_{0}^{\mathrm{r}} \mathrm{r} \varepsilon\left(\mathrm{r}^{\prime}\right)\left[\mathrm{u}_{\mathrm{z}}\left(\mathrm{r}^{\prime}\right)-\mathrm{D}_{\mathrm{zz}}\left(\mathrm{r}^{\prime}\right) \mathrm{k}_{\mathrm{z}}\right] \mathrm{dr}
$$

An average flux for a cross-section of the column can now be defined as

$$
J=\frac{\int_{0}^{R} r \varepsilon(r) u_{z}(r) C(r, z) d r}{\int_{0}^{R} r \varepsilon(r) d r}-\frac{\int_{0}^{R} \varepsilon(r) r D_{z z}(r) d r}{\int_{0}^{R} r \varepsilon(r) d r} \frac{\partial \bar{C}}{\partial z}=T_{1}-T_{2}
$$

Substituting Equation (2.12) for $\mathrm{C}(\mathrm{r}, \mathrm{z})$ in the first term of Equation (2.20), the integral involved can be dropped, giving the following expression for $\mathrm{T} 1$ :

$$
\mathrm{T} 1=\frac{\partial \overline{\mathrm{C}}(\mathrm{z})}{\partial \mathrm{z}} \frac{\int_{0}^{\mathrm{R}} \mathrm{r} \varepsilon(\mathrm{r}) \mathrm{u}_{\mathrm{z}}(\mathrm{r}) \mathrm{I} 2(\mathrm{r}) \mathrm{dr}}{\int_{0}^{\mathrm{R}} \mathrm{r} \varepsilon(\mathrm{r}) \mathrm{dr}}=-\mathrm{D}_{\text {Taylor }} \frac{\mathrm{d} \overline{\mathrm{C}}_{\mathrm{z}}}{\mathrm{dz}}
$$

The second term in Equation 2.20 can be written as

$$
\mathrm{T} 2=\overline{\mathrm{D}}_{\mathrm{zz}} \frac{\mathrm{d} \overline{\mathrm{C}}_{\mathrm{z}}}{\mathrm{dz}}
$$

Therefore,

$$
\begin{aligned}
& J=-\frac{\partial \bar{C}(z)}{\partial z}\left[D_{\text {Taylor }}+\bar{D}_{z z}\right] \\
& D_{\text {eff }}=D_{\text {Taylor }}+\bar{D}_{z z}
\end{aligned}
$$

From the above analysis it is possible to estimate the contributions of convection (Taylor dispersion) and turbulence to the one-dimensional axial dispersion coefficient. The Taylor dispersion coefficient, $\mathrm{D}_{\text {taylor }}$, and the averaged axial eddy diffusivity, $\overline{\mathrm{D}}_{\mathrm{zz}}$, can be directly evaluated from turbulent diffusivities and liquid velocities obtained by CARPT experiments, and from the gas holdup profiles obtained by CT. This will be discussed in a subsequent quarterly. 


\subsection{Nomenclature}

C liquid tracer concentration, $\mathrm{mol} / \mathrm{cm}^{3}$

$\overline{\mathrm{C}} \quad$ cross-sectional averaged concentration, $\mathrm{mol} / \mathrm{cm}^{3}$

$\mathrm{C}^{\prime} \quad$ concentration variation around the mean, $\mathrm{mol} / \mathrm{cm}^{3}$

$\mathrm{C}_{0} \quad$ constant in Equation (2.14)

D . turbulent eddy diffusivity tensor

$D_{\text {eff }} \quad$ effective axial dispersion coefficient defined by Equation (2.24)

$\mathrm{D}_{\mathrm{ax}} \quad$ axial dispersion coefficient, $\mathrm{cm}^{2} / \mathrm{s}$

$D_{\mathrm{rr}}, \mathrm{D}_{\mathrm{zz}}, \mathrm{D}_{\theta \theta} \quad$ diagonal elements of eddy diffusivity tensor, $\mathrm{cm}^{2} / \mathrm{s}$

$D_{\mathrm{rz}}, \mathrm{D}_{\mathrm{r} \theta}, \mathrm{D}_{\mathrm{z} \theta}$ off-diagonal elements of eddy diffusivity, $\mathrm{cm}^{2} / \mathrm{s}$

$\mathrm{D}_{\text {Taylor }} \quad$ Taylor dispersion coefficient, $\mathrm{cm}^{2} / \mathrm{s}$

$\overline{\mathrm{D}}_{\mathrm{r}}, \overline{\mathrm{D}}_{\mathrm{zz}} \quad$ averaged radial and axial eddy diffusivities, $\mathrm{cm}^{2} / \mathrm{s}$

$\mathrm{I} 2(\mathrm{r}), \mathrm{I}(\mathrm{r}) \quad$ functions defined by Equation (2.18) and (2.19)

$\mathrm{J}$

$\mathrm{k}_{\mathrm{z}}$ average flux across the cross section of the column, $\mathrm{mol} / \mathrm{cm}^{2} / \mathrm{s}$

constant in equation (2.14)

$\vec{n}_{k} \quad$ unit normal vector in phase $k$

$\mathrm{R} \quad$ coordinate in $\mathrm{r}$ direction, $\mathrm{cm}$

$\mathrm{T}$ time, $\mathrm{s}$

$T_{1}, T_{2} \quad$ functions defined by Equations (2.21) and (2.22)

$\mathrm{u}_{\mathrm{r}}, \mathrm{u}_{\mathrm{z}} \quad$ velocity in $\mathrm{r}$ and $\mathrm{z}$ direction, $\mathrm{cm} / \mathrm{s}$

$\overrightarrow{\mathrm{u}} \quad$ Eulerian velocity, $\mathrm{cm} / \mathrm{s}$

$\overrightarrow{\mathrm{u}}_{\mathrm{k}} \quad$ velocity vector in phase $\mathrm{k}, \mathrm{cm} / \mathrm{s}$

$\overrightarrow{\mathrm{u}}_{\mathrm{ki}} \quad$ interfacial velocity vector, $\mathrm{cm} / \mathrm{s}$

$\mathrm{u}_{\mathrm{r}}^{\prime}, \mathrm{u}_{\mathrm{z}}$ fluctuation velocity in $\mathrm{r}$ and $\mathrm{z}$ directions, $\mathrm{cm} / \mathrm{s}$

$\overrightarrow{\mathrm{x}} \quad$ position vector

$X_{k} \quad$ phase (k) function

$\mathrm{Z} \quad$ coordinate in $\mathrm{z}$ direction, $\mathrm{cm} / \mathrm{s}$

\section{Greek symbols}

$\begin{array}{ll}\varepsilon & \text { phase holdup } \\ \varepsilon_{\mathrm{k}} & \text { holdup of phase } \mathrm{k} \\ \rho_{\mathrm{k}} & \text { density of phase } \mathrm{k}\end{array}$




\subsection{References}

1. Myers, K. J., "Liquid Phase Mixing in Churn Turbulent Bubble Columns," D. Sc. Thesis, Washington University, St. Louis, MO, 1986.

2. Ohki, Y. and H. Inoue, "Longitudinal Mixing of the Liquid Phase in Bubble Columns," Chem. Eng. Sci., Vol. 25, 1-16 (1970).

3. Hinze, J. O., "Turbulence," McGraw-Hill, New York (1975).

4. Seinfeld, J. H., "Atmospheric Chemistry and Physics of Air Pollution," Wiley Publications, New York (1986).

5. Tennekes, H. and J. L. Lumley, "A First Course on Turbulence," The MIT Press, Cambridge (1972).

\section{Progress in Evaluation of the Momentum Balance Equation for Bubble Columns Using CARPT and CT Measurements}

\subsection{Introduction}

Experimentally determined gas holdup and Reynolds stresses in a 14-cm-diameter bubble column were used to evaluate the dominant terms in the radial momentum balance equation using a two-fluid model approach. (The detailed analysis was reported in the $10^{\text {th }}$ quarterly report). The following assumptions were made in the formulation of the problem:

1. Viscous effects are negligible for both phases.

2. Gas inertial effects are negligible.

3. Mean radial drag force is negligible.

4. Wall effects are not included.

5. Radial components of the virtual mass and lift forces are negligible.

6. Gas-liquid velocity correlations are small.

These assumptions resulted in the following simplified radial momentum balance equation:

$$
\frac{d}{d r}\left(r \alpha^{l} \overline{u_{r}^{\prime l} u_{r}^{\prime \prime}}\right)=\alpha^{l} \overline{u_{\theta}^{\prime l} u_{\theta}^{\prime l}}+\frac{r \overline{F_{r}^{T}}}{\rho^{l}\left(\alpha^{l}-1\right)}
$$

where $\overline{F_{r}^{T}}$ is the fluctuating component of the drag force in the radial direction. Two models were used to evaluate the momentum budget in the bubble column. First, the fluctuating component of the radial drag force was ignored. This yielded the following equation:

$$
\frac{d}{d r}\left(r \alpha^{l} \overline{u_{r}^{\prime \prime} u_{r}^{\prime \prime}}\right)=\alpha^{l} \overline{u_{\theta}^{\prime l} u_{\theta}^{\prime l}}
$$

In the second model, an approach for modeling the turbulent drag force, as proposed by Jakobsen (1993) and Sannaes (1997), was used. The resulting expression for the turbulent drag force was inserted in eq. (3.1), and the following equation was obtained:

$$
\frac{d}{d r}\left(r \alpha^{l} \overline{u_{r}^{\prime l} u_{r}^{\prime \prime}}\right)=\alpha^{l} \overline{u_{\theta}^{\prime l} u_{\theta}^{\prime l}}-\frac{3}{4} \frac{r}{\rho^{l}} \alpha^{l} \frac{\mu_{l}}{d_{s}^{2}} C_{D}\left(\frac{d_{p}}{v_{l}}\right)^{2} \overline{\frac{w_{z}}{\operatorname{Re}_{p}}} \overline{w_{z}^{\prime} w_{r}^{\prime}}
$$

By plotting the left-hand side (L.H.S.) of eq. (3.2) and eq. (3.3) versus the right-hand side (R.H.S.), the accuracy of the assumptions made in deriving the above equations was evaluated 
for both models. The analysis showed a discrepancy near the wall between the two sides for both equation (3.2) and equation (3.3). The results of this analysis for a 14-cm-diameter bubble column at gas superficial velocities of $U_{g}=4.8$ and $12 \mathrm{~cm} / \mathrm{s}$, and a $19-\mathrm{cm}$-diameter column at $U_{g}$ $=4.8 \mathrm{~cm} / \mathrm{s}$ have been reported in the previous quarterly report no. 10 .

This analysis was repeated for a new set of experimental data obtained in a 10-cm-diameter bubble column at $U_{g}=2$ and $8 \mathrm{~cm} / \mathrm{s}$. In these experiments, both holdup and velocity field were measured in the same system (same water, same impurities, etc.), unlike the previously treated data for which holdup and velocity measurements had been performed during different measurement campaigns.

Figure 3.1 shows the results obtained from equation (3.2) for the 10-cm-diameter column. In this figure, the L.H.S. of equation (3.2) is plotted versus the R.H.S. It can be seen that there is a significant mismatch between the two sides of eq. (3.2) for $U_{g}=8 \mathrm{~cm} / \mathrm{s}$, while a reasonable agreement is obtained for $U_{g}=2 \mathrm{~cm} / \mathrm{s}$. These results confirm the previously reported observations.

In this report, the possible sources of the observed discrepancies are discussed.

\subsection{Discussion}

The first step in searching for the cause of the above-mentioned discrepancies was to determine the validity of the initial assumptions 1 to 5 . These were checked and confirmed by the following arguments:

1. Turbulent viscosities are orders of magnitude higher than molecular viscosities. The typical values of the terms corresponding to viscous stresses in the radial direction are on the order of 0.0001 to $0.01 \mathrm{~cm}^{2} / \mathrm{s}^{2}$ compared to the typical values of the Reynolds stress terms, which range from 25 to $400 \mathrm{~cm}^{2} / \mathrm{s}^{2}$.

2. Gas density is three orders of magnitude (1/1000) smaller than liquid density in an air-water system at ambient pressure and temperature. Hence, gas inertial effects are negligible.

3. Mean radial slip velocity is negligible, and the momentum exchange coefficient is small, which makes the mean drag force term negligible compared to the Reynolds stress terms. The typical values of the radial drag force term are about $1 \mathrm{~cm}^{2} / \mathrm{s}^{2}$, while the typical values of the Reynolds stress terms range from 25 to $400 \mathrm{~cm}^{2} / \mathrm{s}^{2}$ for different cases. Thus, the mean radial drag is negligible.

4. The analysis is performed by using velocity and holdup data only in the region from 0 to 0.85 dimensionless radius; hence, wall effects are not captured and thus should not influence our analysis.

5. Radial components of added mass and lift forces are also negligible for the same reasons as in the case of the mean radial drag force, discussed in (3) above.

The following additional investigations were also conducted to detect the possible sources of error related to the assumption of fully developed flow and variability in determination of the Reynolds stress and gas hold-up profiles, as well as the uncertainty in estimation of the gas velocity profile. 
1. The fully developed flow condition requires that the velocity (and hence, the Reynolds stress) profiles do not vary in the axial direction. In order to evaluate the validity of this assumption, the Reynolds stress profiles were examined at different heights in the middle section of the column and compared for all cases. All the profiles showed similar increasing or decreasing trends, and discrepancies in their shape and magnitude were relatively small. This fact is illustrated in Figures 3.2 and 3.3, where the normal Reynolds stress profiles at different heights in the middle section of the column are compared in a column with $D_{c}=14 \mathrm{~cm}$ and at $U_{g}=12 \mathrm{~cm} / \mathrm{s}$. Hence, variations in Reynolds stress profiles cannot explain the observed discrepancies.

2. The uncertainty in measured Reynolds stresses was examined next. The error bars for all of the radial profile data points are comparable (Degaleesan, 1997), and this is not the source of the observed differences. Figure 3.4 shows an example of the uncertainty in determination of the Reynolds stresses for the case of $D_{c}=14 \mathrm{~cm}$.

3. The radial gas holdup profile was examined next. The following equation was used for smoothing the measured gas holdup profiles:

$$
\alpha_{g}(\xi)=\tilde{\alpha}\left(\frac{m+2}{m}\right)\left(1-c \xi^{m}\right)
$$

A careful analysis of the gas holdup profiles for different axial positions in the so-called fully developed section of flow yielded the values of $m$ and $c$, which vary significantly with height. Different holdup profiles were tested, and it was found that the match between the two sides of eq. (3.1) is very sensitive to the holdup gradient, especially at high superficial gas velocity. For all three cases, the deviation between the R.H.S. and the L.H.S. of eq. (3.1) starts at about 0.6 to 0.7 in dimensionless radius, which matches the break point of the holdup profiles (typical values of $m$ range from 2.5 to 4 in the case of $12 \mathrm{~cm} / \mathrm{s}$ superficial gas velocity in the 14-cm column). By increasing the coefficient $m$ from 3.5 (the average value) to 4.5 , a good agreement could be found for the case of high gas superficial velocity. The effect of $m$ on equation (3.2) for $D_{c}=14 \mathrm{~cm}$ and $U_{g}=12 \mathrm{~cm} / \mathrm{s}$ is shown in Figure 5. The value of $c$ does not play a significant role in the calculations, since we have excluded the wall from our analysis. The change in the holdup parameters had a much smaller effect in the cases with lower superficial gas velocities. This fact is illustrated in Figure 6 for $D_{c}=14 \mathrm{~cm}$ and $U_{g}=4.8$ $\mathrm{cm} / \mathrm{s}$ by examining the results for $m=3$ and $m=4.5$. Hence, the radial gas holdup profile variations with axial position may account for some of the observed mismatch in the radial momentum balance.

4. The sensitivity of the results to the assumed gas velocity profiles was examined, and was found to be only a small source of error, as illustrated in Figure 3.7, where the results have been plotted for two different gas velocity profiles.

5. Finally we examined our assumption 6 of negligible gas-liquid correlation. Ignoring the correlations between gas and liquid velocities that arise in the formulation of the turbulent drag force by this method seems to be unjustified. The addition of these terms can change the sign of the turbulent drag force. Unfortunately, experimental methods do not exist at present for the measurement of these correlations. Therefore, the development of a closure model for these correlations is an important but difficult task that should be considered in the future work on CFD simulations using the two-fluid model approach. A theoretical approach proposed by Simonin (1996) can be used for determination of the gas-liquid velocity 
correlations. In the simplest form of this approach, it can be assumed that the particles (bubbles) are only locally entrained by the fluid, hence, this method is called the "local entrainment approach." In this approach, the standard fluid Lagrangian time-scale, the fluid Lagrangian time-scale measured along the particles path (i.e., the Lagrangian time scale "seen" by the particles) and the particle relaxation time should be known. The gas-liquid velocity covariance can be calculated from this information and the individual phase velocity fields. The gas-liquid velocity correlations are expressed in terms of this covariance, and the gas and liquid phase velocity gradients, by using a Boussinesq type closure model. Our preliminary analysis using this model has shown that the change in the turbulent drag force due to consideration of the gas-liquid velocity correlations is small. However, the uncertainty in determination of different time scales, and the difficulty in checking the validity of the model assumptions, makes the final judgment difficult. The description of the method for determination of gas-liquid velocity covariance using the experimental data will be the subject of the future report, where this matter will be discussed in more detail.

\subsection{Conclusion}

In conclusion, it seems that the error in estimation of hold-up profiles has considerable effect on the match between the two sides of the momentum balance in the radial direction, especially at higher superficial gas velocity.

The lack of ability to measure gas-liquid velocity correlations make the evaluation of their relative importance in determination of the turbulent drag force a difficult task.

The numerical error in determination of the derivative term on the L.H.S. of eq. (3.1) can be another important source of error. More experimental points are needed close to the wall, where the gradients are steeper. A careful analysis should also be made of the effect of filtering on determination of Reynolds stresses by the CARPT technique.

\subsection{Nomenclature}

$\begin{array}{ll}C_{D} & \text { Drag force coefficient } \\ D_{p} & \text { Bubble diameter } \\ D_{s} & \text { Sauter mean diameter } \\ F & \text { Drag Force } \\ R & \text { Radial coordinate } \\ R e & \text { Reynolds number } \\ U & \text { Velocity } \\ W & \text { Slip velocity }\end{array}$

Greek letters

$\begin{array}{ll}\alpha & \text { Hold-up } \\ \mu & \text { Viscosity } \\ \rho & \text { Density } \\ \theta & \text { Azimuthal coordinate }\end{array}$

Subscripts

$R$

Radial coordinate 


$\begin{array}{ll}Z & \text { Axial coordinate } \\ I & \text { General space coordinate } \\ \theta & \text { Azimuthal coordinate }\end{array}$

Superscripts

\begin{tabular}{ll}
- & Mean \\
$L$ & Fluctuation about mean \\
$G$ & Liquid \\
$T$ & Gas \\
$D$ & Turbulent \\
\hline & Drag
\end{tabular}

\subsection{References}

1. Degaleesan S., "Fluid Dynamic Measurements and Modeling of Liquid Backmixing in Bubble columns", D.Sc. Thesis, Washington University, St. Louis (1997).

2. Jakobsen S.A., "On the Modelling and Simulation of Bubble Column Reactors Using TwoFluid Model", Dr. Ing. Thesis, Norwegian University of Science and Technology, Trondheim (1993).

3. Kumar S. B., "Computed Tomographic Measurements of Void Fraction and Modeling of the Flow in Bubble Columns", D.Sc. Thesis, Washington University, St. Louis (1994).

4. Sannaes B.H., "Solid Movement and Concentration Profiles in Column Slurry Reactors", Dr. Ing. Thesis, Norwegian University of Science and Technology, Trondheim (1997).

5. Simonin O., "Combustion and Turbulence in Two-Phase Flows - Continuum Modelling of Dispersed Two-Phase Flows", von Karman Institute for Fluid Dynamics, Lecture series 199602, 1996. 


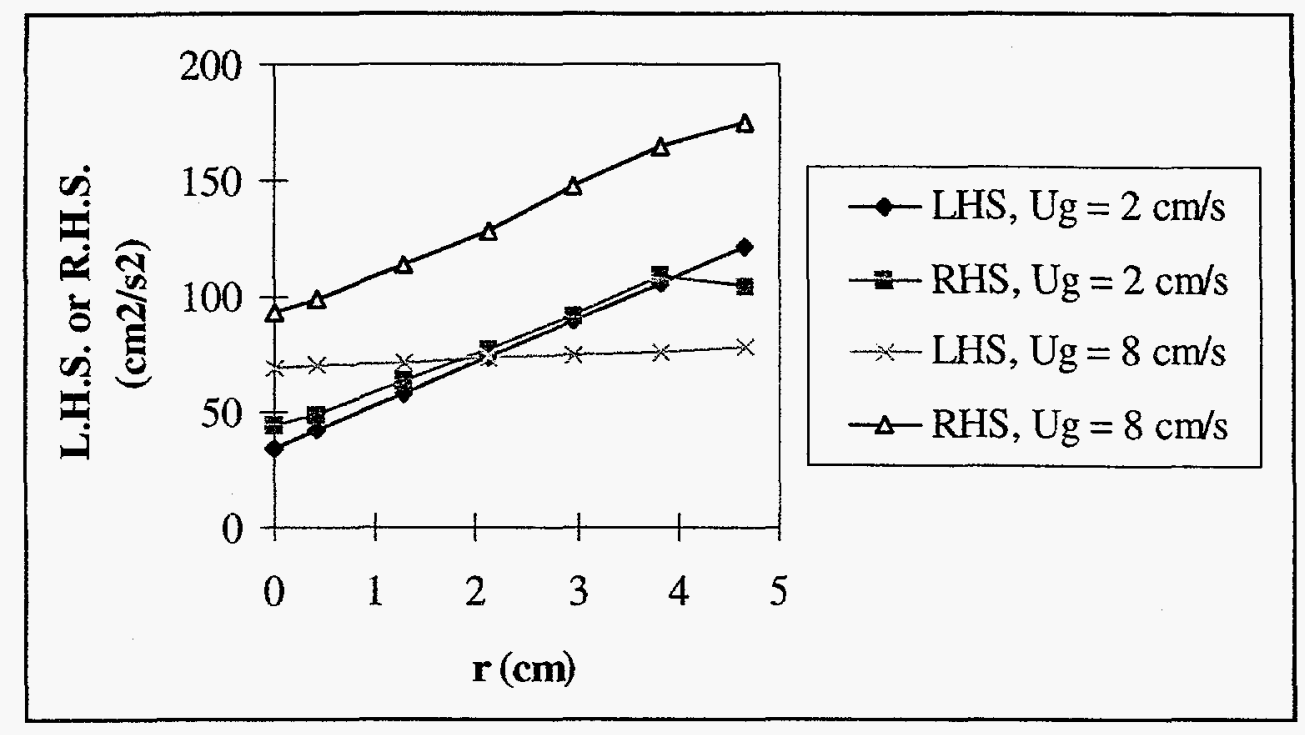

Figure 3.1. The analysis of radial momentum balance for $10 \mathrm{~cm}$ diameter bubble column using equation (3.2).

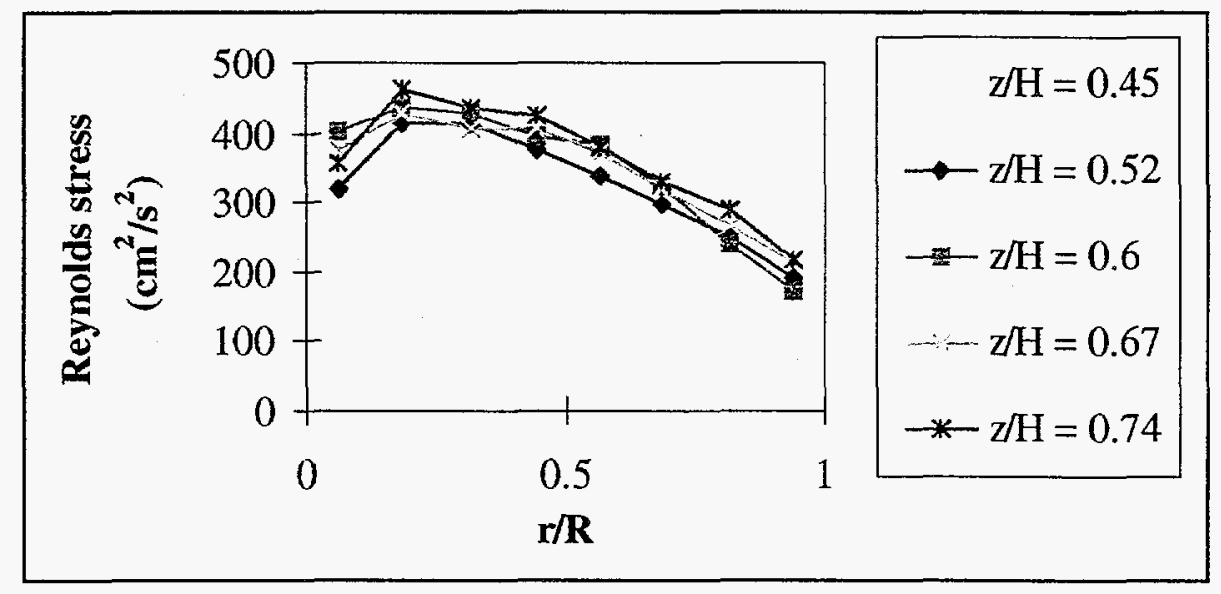

Figure 3.2. Radial profiles of the normal Reynolds stresses in the radial direction, $\overline{u_{r}^{\prime l} u_{r}^{\prime \prime}}$, at different axial positions $\left(D_{c}=14 \mathrm{~cm}\right.$ and $\left.U_{g}=12 \mathrm{~cm} / \mathrm{s}\right)$. 


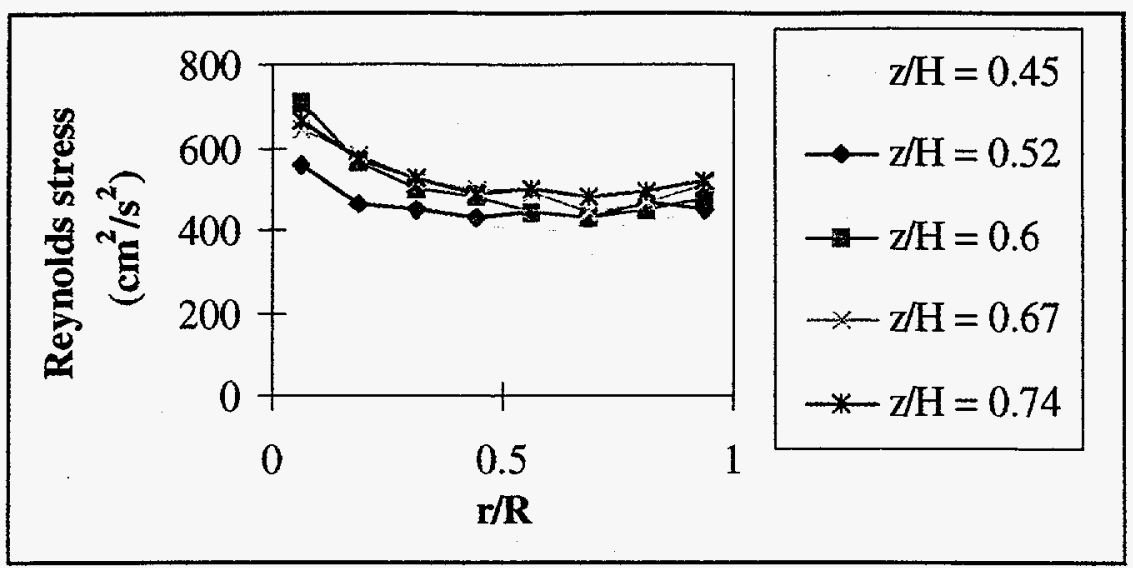

Figure 3.3. Radial profiles of the normal Reynolds stresses in the azimuthal direction, $\overline{u_{\theta}^{\prime \prime} u_{\theta}^{\prime l}}$, at different axial positions $\left(D_{c}=14 \mathrm{~cm}\right.$ and $\left.U_{g}=12 \mathrm{~cm} / \mathrm{s}\right)$. 


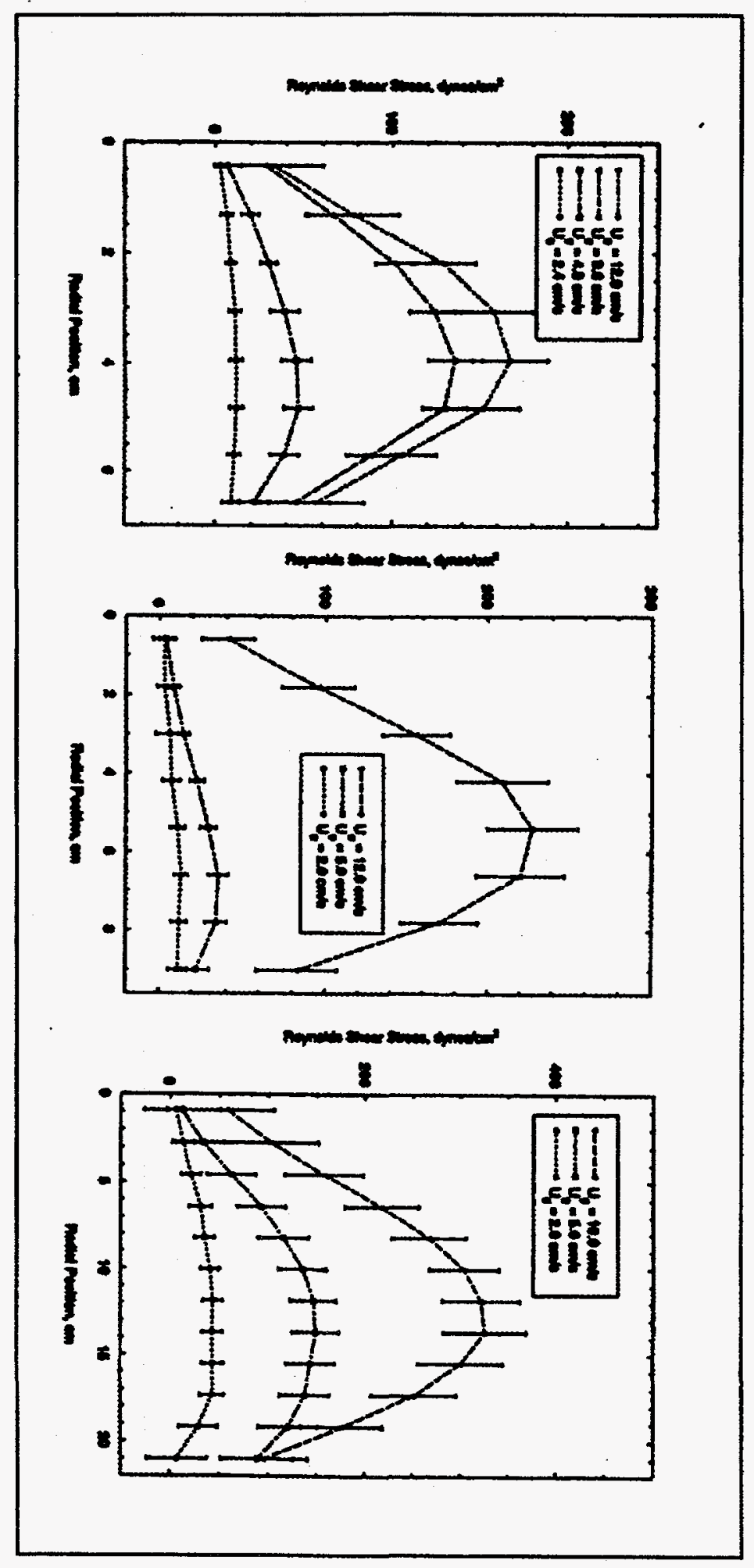

(a)

(b)

(c)

Figure 3.4. Spread of Reynolds stress data about the average profile for CARPT measurements in (a) $D_{c}=14$ (a) $D_{c}=19$ (b) and $D_{c}=44$ (c) cm bubble columns at $U_{g}=2$ to $12 \mathrm{~cm} / \mathrm{s}$ 


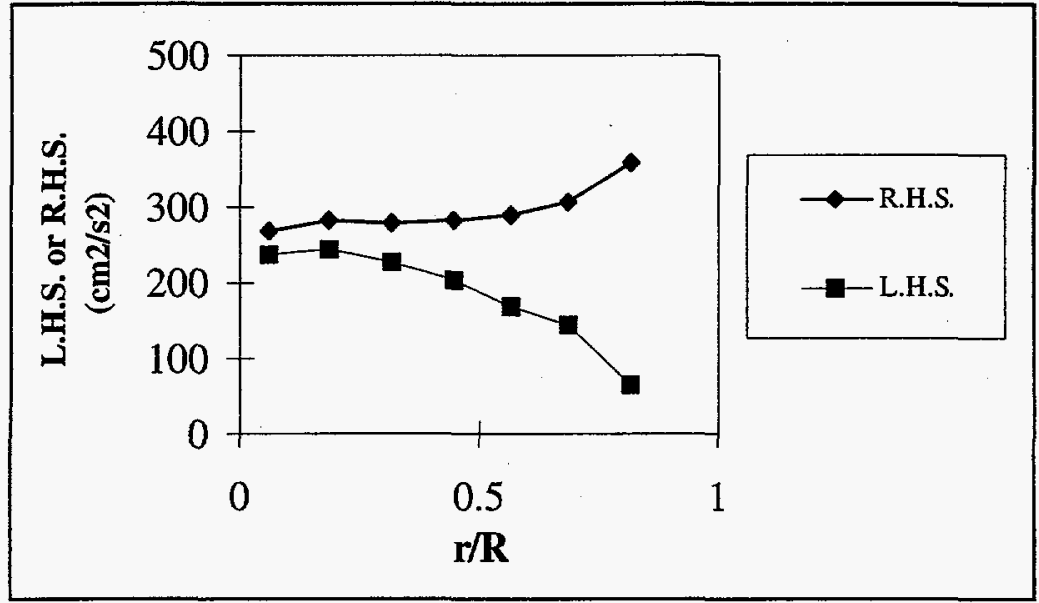

(a)

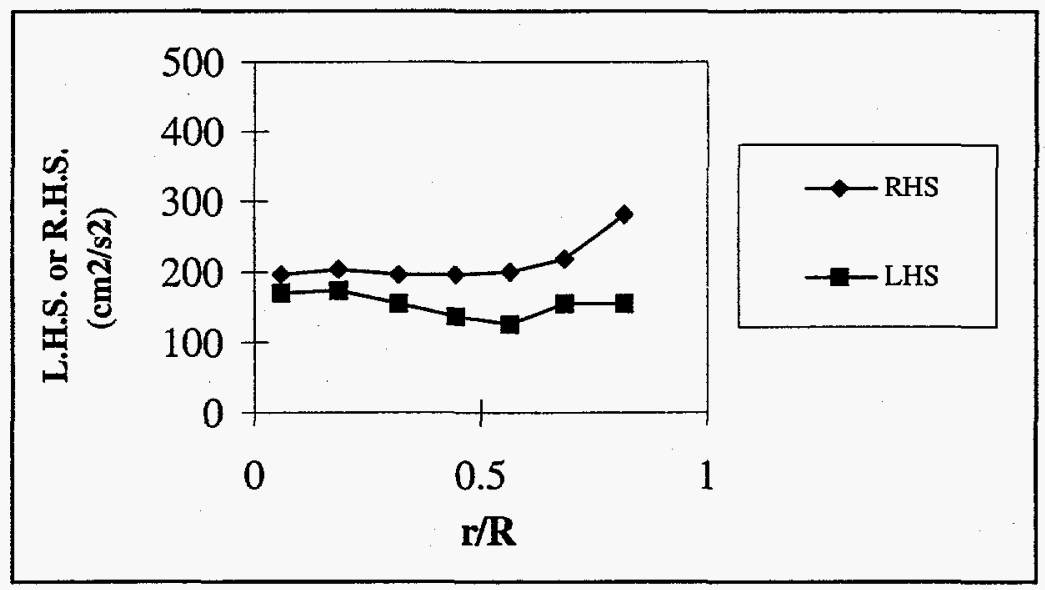

(b)

Figure 3.5. RHS and LHS of equation (3.2) plotted for $D_{c}=14 \mathrm{~cm}$ and $U_{g}=12 \mathrm{~cm} / \mathrm{s}$ using holdup profiles with different values of $m$ (a) $m=3.5$ (b) $m=4.5$ 


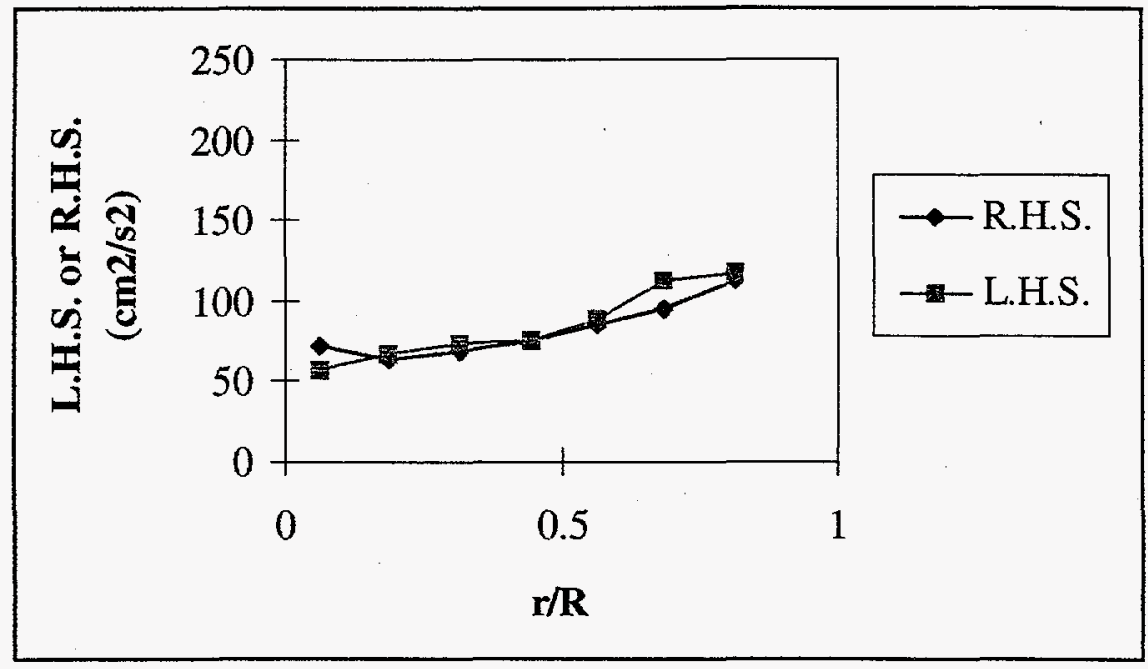

(a)

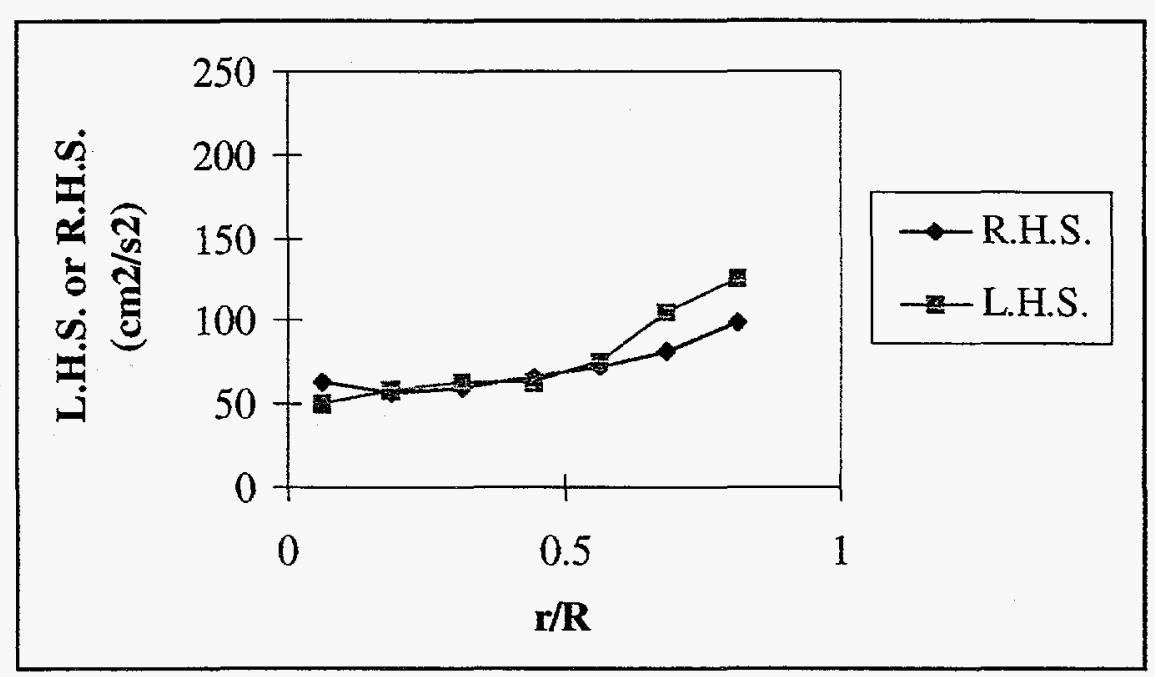

(b)

Figure 3.6. RHS and LHS of equation (3.2) plotted for $D_{c}=14 \mathrm{~cm}$ and $U_{g}=4.8 \mathrm{~cm} / \mathrm{s}$ using hold-up profiles with different values of $m$ (a) $m=3$ (b) $m=4.5$ 


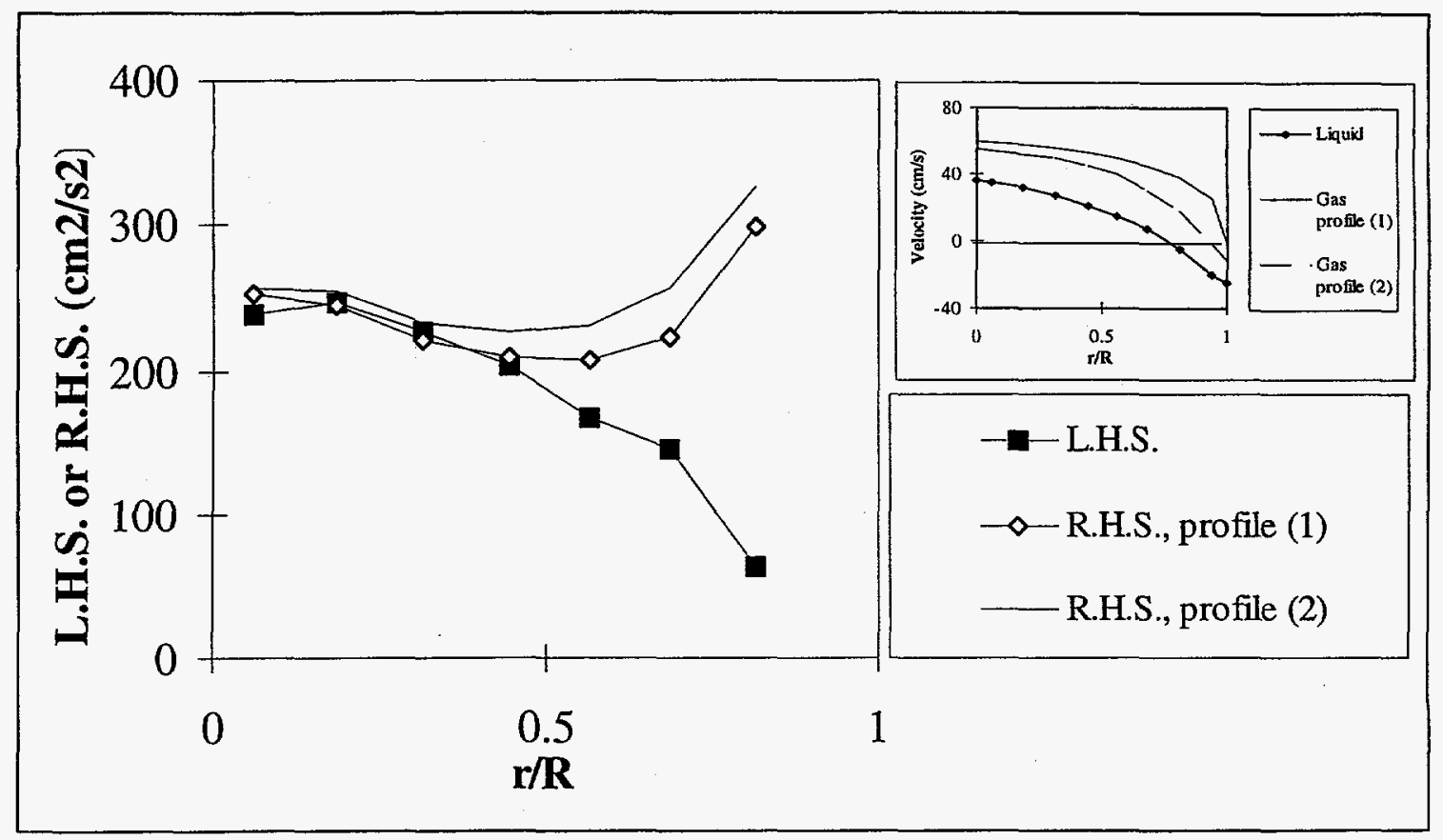

Figure 3.7. Effect of gas velocity profile on the RHS of equation (3.1) for $D_{c}=14 \mathrm{~cm}$ and $U_{g}=12 \mathrm{~cm} / \mathrm{s}$ 